
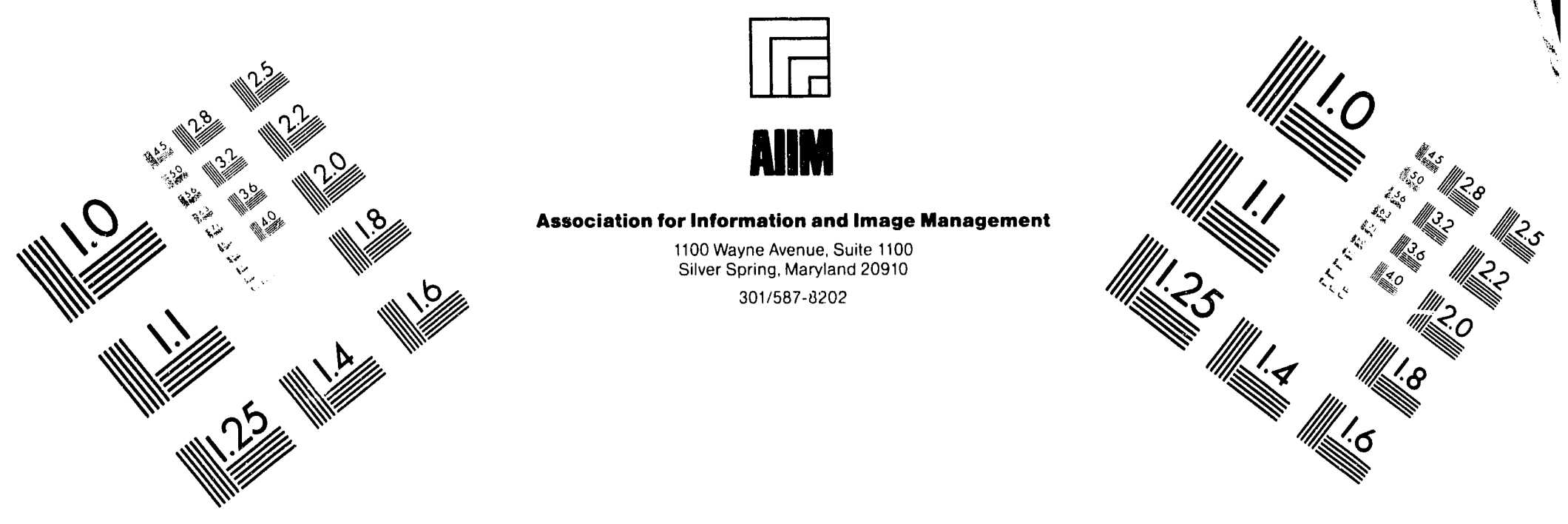

\title{
Centimeter
}

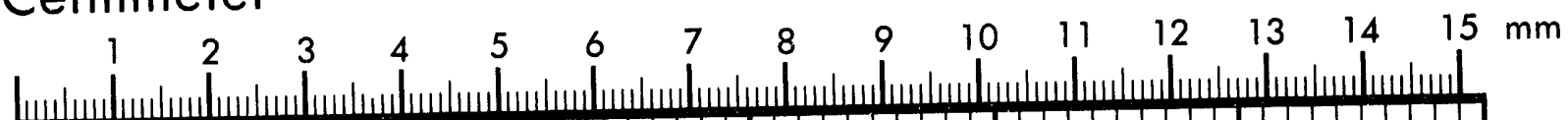
| Inches
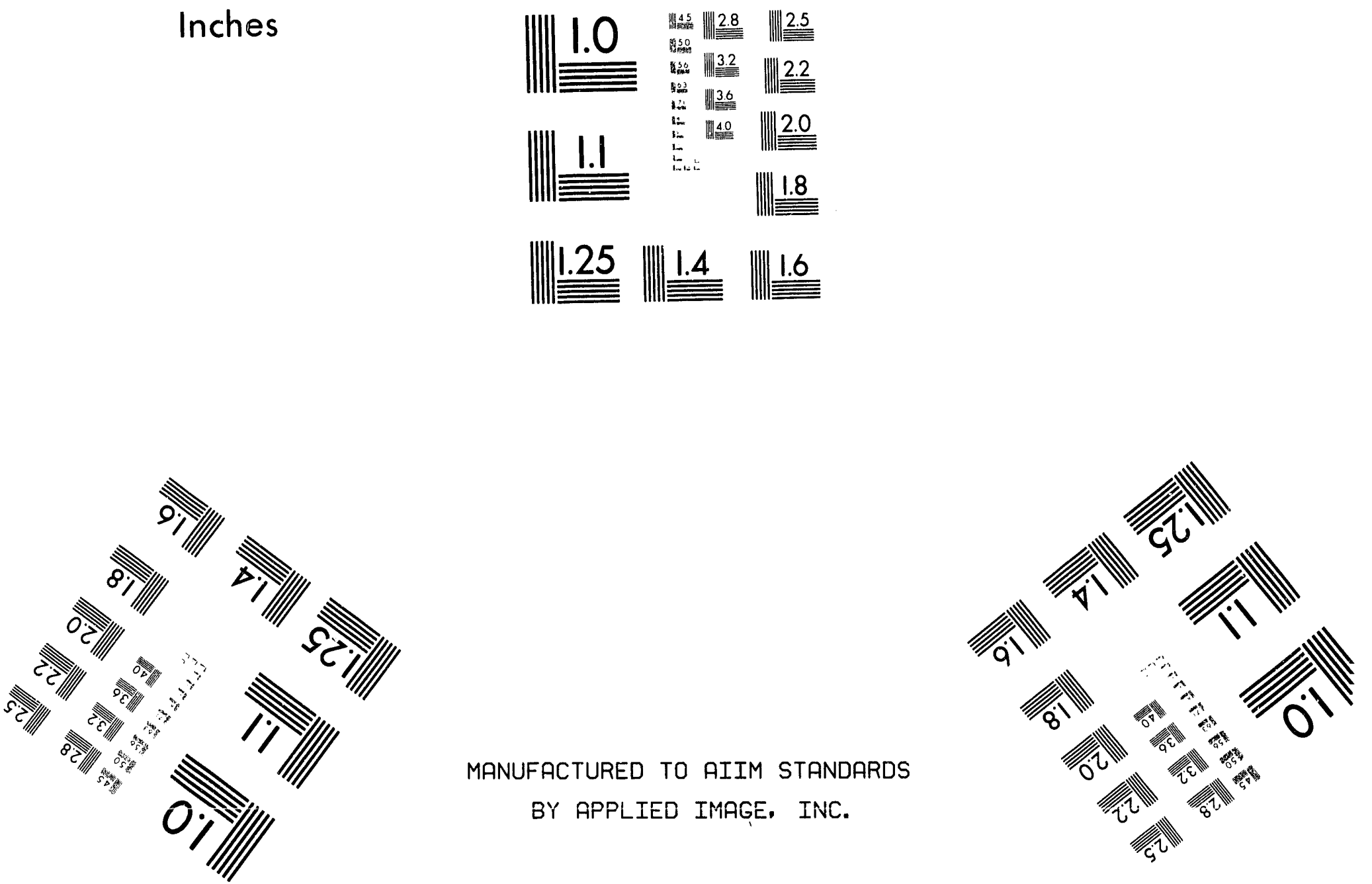

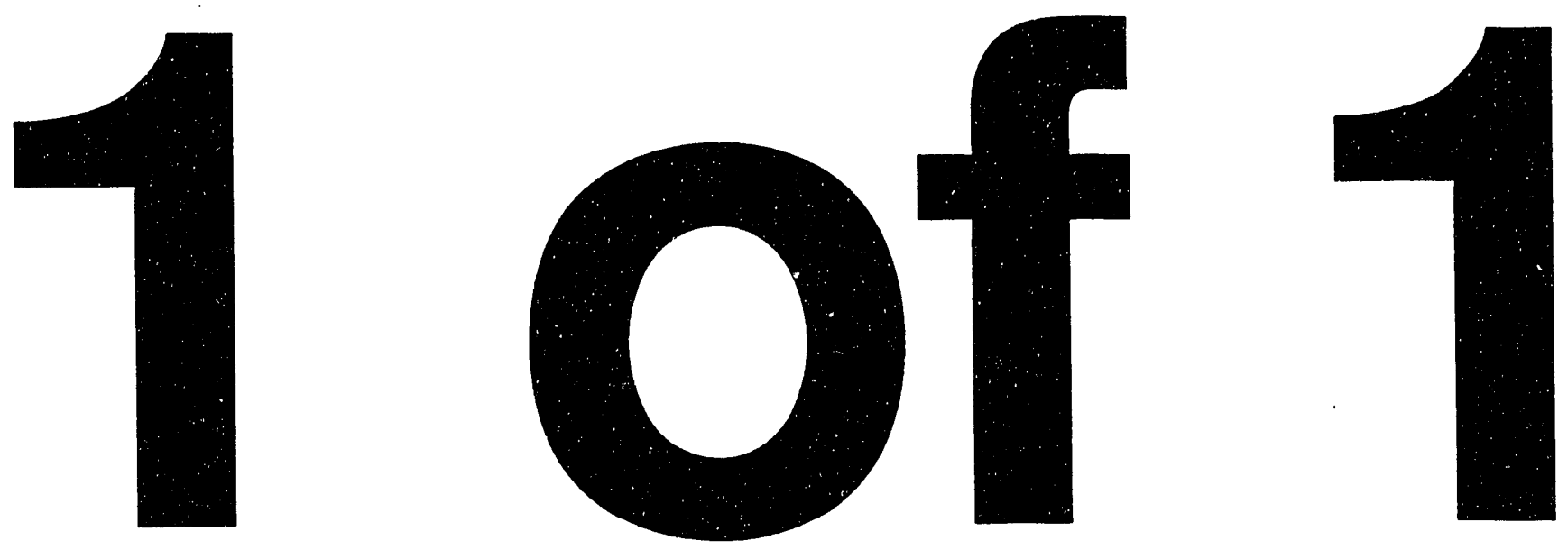


\section{MARKAL-MACRO: An Overview}

Leonard D. Hamilton, Gary A. Goldstein, John Lee, Alan S. Manne,*

William Marcuse, Samuel C. Morris, and Clas-Otto Wene**

* Stanford University

**Brookhaven National Laboratory and

Chalmers University of Technology

November 12, 1992

BIOMEDICAL AND ENVIRONMENTAL ASSESSMENT GROUP

ANALYTICAL SCIENCES DIVISION

DEFARTMENT OF APPLIED SCIENCE

BROOKHAVEN NATIONAL LABORATORY

ASSOCIATED UNIVERSITIES, INC.

Under Contract No. DE-AC02-76CH00016 with the

U. S. Department of Energy 


\section{ACKNOWLEDGMENTS}

This project was supported by the Office of Program Analysis, Office of Energy Research, and by the Office of Environmental Analysis, Office of Policy, Planning and Analysis, U. S. Department of Energy.

This work was initiated when one of the authors (Wene) was a Visiting Scientist at Brookhaven National Laboratory. He thanks Dr. George Jordy for suggesting this stay, and for insisting that MARKAL should have an economic driver. He also thanks Dr. Leonard Hamilton and his colleagues at the Biomedical and Environmental Assessment Group for their support during his visit.

We are much indebted to Sung-ho Ahn for his contributions to developing an all-GAMS version of the MARKAL-MACRO model. See Ahn (1992). 


\section{TABLE OF CONTENTS}

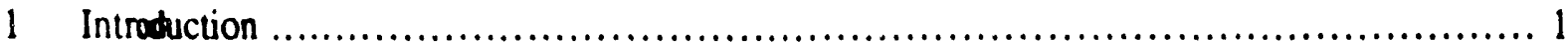

1.1 Linking Energy and Economy-wide Models .................................. 1

1.2 MARKAL and MACRO ............................................................. 2

1.3 Organization of this Report ................................................. 3

2 MARKAL, MACRO and the Linkage Approach ...................................... 4

2.1 The Basic Concepts ............................................................. 4

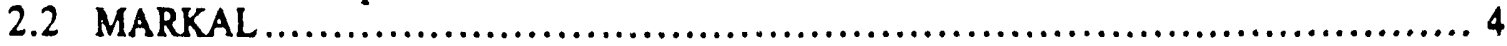

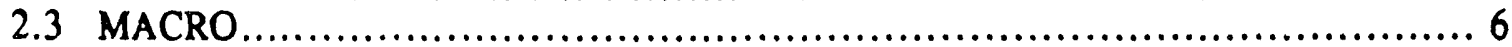

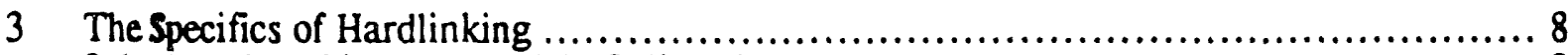

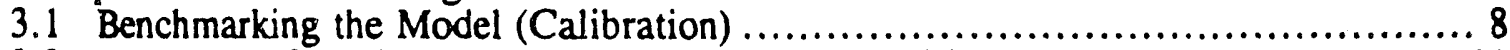

3.2 Treatment of Capital Charges and Residual Capacities.............................11

3.3 Full vs. Differential Costing .............................................. 12

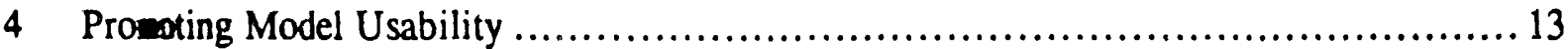

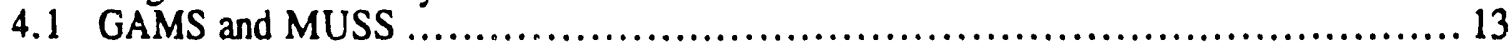

4.2 Modeling Language and Optimizer (GAMS/MINOS) ........................ 13

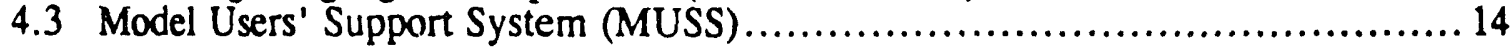

5 Modd Results......................................................................... 16

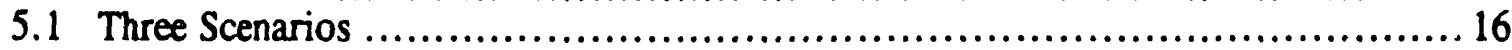

5.2 Impact on the Energy System ................................................. 17

5.3 Impact on Carbon Emissions ............................................... 18

5.4 Impact on the Economy ........................................................ 18

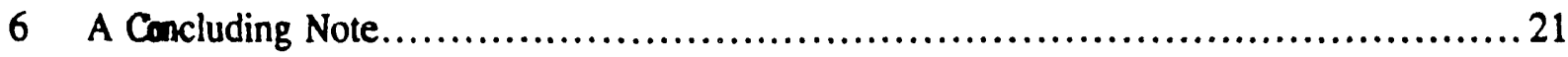

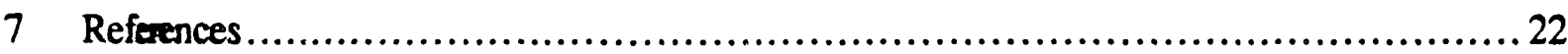

Appendix A: Formulation of the MACRO Submodel and Linkage Equations ...............45

\section{FIGURES}

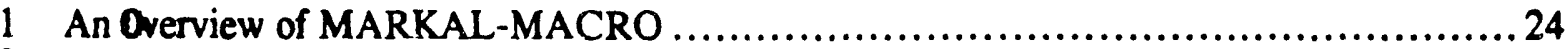

2 MARKAL/MARKAL-MACRO Users Support System .................................. 25

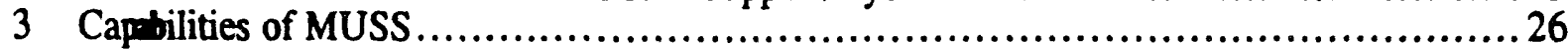

4 Base Case: Primary Energy Use ......................................................... 27

5 Primary Energy use in each Scenario .......................................................... 28

6 Tot Useful Energy Demand..........................................................29

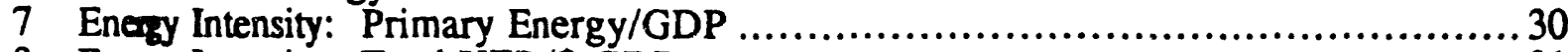

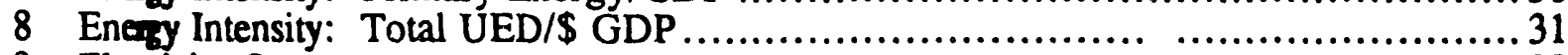

9 Electicity Output................................................................... 32

10 Eleticity Output by Fuel used for Generation .......................................... 33

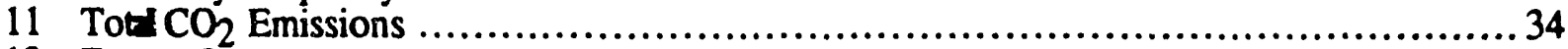

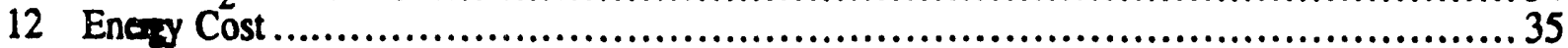

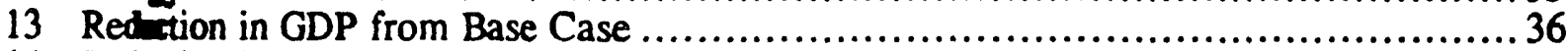

14 Redetion in Investment from Base Case ............................................................... 37

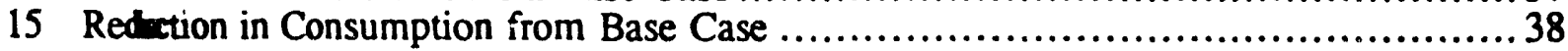


16 Redaction in Energy Cost form Base Case ............................................ 39

17 Price of Residential Water Heat ..................................................... 40

18 Price of Commercial Space Heat .................................................... 41

19 Price of Automobile Transport ..................................................... 42

20 Price of Industrial Process Heat ........................................................... 43

21 Shadow Price of Carbon Emissions................................................... 44

\section{TABLES}

1 Useful Energy Demand Projections Employed in MARKAL ............................. 10

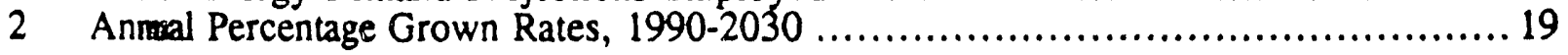


Etroduction

1.1 Linking energy and conorny-wide model

MARKAL-MACRO is an experiment in model linkage. This new tool is intended as an improment over existing methods for energy policy assessment. It is designed specifically for estimaing the coots and analyzing alternative technologies and policics proposed for reducing enviramental risks such as global climate change or regional air pollution.

The greenhouse gas debate illustrates the usefulness of linked energy-economy models. A centralisue is the coupling between economic growth, the level of energy demands, and the evolution of an axgy aystem to supply these demands. The debate is often connected with alternative modeling approdea. The competing philosophies may be labeled "top-down macroeconomic" and "bottom-up enginesing" perspectives.

Do macroeconomic models, with their descriptions of effects within the lotal economy but few technim details on the energy system, lend to overestimate future energy demands? Conversely, do enginering models, ignoring feedbacks to the general economy and non-technical market factors but containg rich descriptions of technology options, tend to take too optimistic a view of conservation and th use of tencwable energy sources? Or is the principal difference that the engineering models ignore vew sources of energy demands, and that the macroeconomic models ignore saturation effects for old cheries of demands?

An efficient modeling tool must have the scope and detail to match the width and depth of the polic rroblem being analyzed. In order to respond to major environmental risks (e.g., the possibility of gledel climate changes), there must be long-range, fundamental changes in the energy system. For an ysia of these changes and an understanding of their nature, the modeling tool must be able to captwe the complex network of relations within the energy system, as well as the opportunities of new or insored technologies.

Changes in the energy system will lead to changes in the relative prices of individual energy carrica If prices rise, there will be price-induced conservation. A major transition would require the realloction of resourees from other parts of the economy. It could affect capital formation and econec growth. Ultimately this would affect the aggregate level of economic activity and the mix of eners deman?: To analyze these indirect effects of emission reductions, we need modeling tools that will ingrate the macroeconomic and the systems engineering approach. 


\subsection{MARKAI, and MACKO}

Good documentation is available for the individual models MARKAl, and MACRO. These each lave a proven track record for energy and environmental use. Sec Rowe and Ilill (1989), Johnason et al. (1992) and Manne and Richelo (1992). In MARKAL-MACRO, these two models are linked brmally. Much of this report is drawn from an carlicr description of the integrated model by Manne and Wene (1992).

Both submodels are dynamic. That is, they are solved under the assumption that there is perfect foresight with respect to changing lechnologies and economic conditions. The alternative would be to adopt recursive dynamics in which decisions are made separately for each time period. The recursive approach has several advantages, but like the cobweb model of agricultural systems, it has the diedvantage of a tendency toward "overshoot and collapse".

MARKAL is a systems engineering (physical process) analysis built on the concept of a Referexe Energy System, RES. See Marcuse et al. (1976) and Fishbone et al. (1983). MARKAL allows detailed description of existing and alternative energy technologies and of existing and alternative paths of energy carriers from their source - through different conversion technologies - to the point of final use. The MARKAL structure makes it possible to build in supply curves of technical conservation. See Wene (1980). Often, however, it is supposed that comprehensive supply curves are too discult to estimate, and price-induced conservation options are therefore omitled.

MARKAL is solved by means of dynamic linear programming. In most applications, the end use demands are fixed, and an economically efficient solution is obtained by minimizing the present value of the energy system's costs throughout the planning horizon.

Generally, MARKAL has been used in a stand-alone mode, but there have been several experiments with informal linkage to other models. The first work along these lines was reported by Hoffinan and Jorgenson (1977). For subsequent work, see Berger et a. (1987) and Yasukawa et al. (1985) We are unaware of previous efforts at "hardlinking" between MARKAL and a long-term macrucosomic growth model.

MACRO takes an aggregated view of long-term economic growth. The basic input factors of protaction are capital, labor and individual forms of energy. The economy's outputs are used for invesent, consumption and interindustry payments for the cost of energy. Investment is used to build up the stock of capital. The model clearly distinguishes between autonomous (i.e., structural trendy) and price-driven conservation.

MACRO is solved by nonlinear optimization. It uses the criterion of maximum discounted utility of consumption to select among alternative time paths of energy costs, macroeconomic 
consumption and investment. MACRO is "Ilynamic" in the same sense an MAllkAl: it Usen look. slicad katures for choices thoughout the planning horizoll. This implies, for instance, that the investment decisions lead to equal benefits for the rollsumer from an additional dollar's worth of currea consumption and the future consumption gencrated by an additional dollar's worth of in vestuent.

Both MACRO and MARKAL are based on the concept of a single representative producerconsumet. Typically, this means that there are no tax or subsidy wedges between the marginal costs of consumption and of production. Neither model provides a direct calculation of impacts on individual industries at, say, the two-digit SIC level. Hitherto, MACRO has been used only in conjunction with ETA, a highly aggregaled Energy Technology Assessment model.

In describing the development of the energy system and providing information about energy costa, MARKAL fulfills the same role as ETA, but it has considerably more technological detail. ETA feature only 8 electric and 9 nonelectric technologies. There is little or no description of the conversion proceses that lie between primary energy sources and the end-use demands.

MARKAL-MACRO employs the newest U.S. version of MARKAL. Time is analyzed in fiveyear tepe, beginning with 1990 as a base year and extending through a planning horizon of 2030. There are 60 energy supply processes and 48 electric conversion lechnologies. The model incorporates seasonal and diurnal variations in the demands for electricity and district beating. There are 120 enduse technologies for supplying the 23 categories of useful energy demands. These are viewed as primary inputs into the MACRO production function.

Uecful energy demands are exogenous parameters in the stand-alone MARKAL, but are determined endogenously within MARKAL-MACRO. As a result of the two-way linkage, useful energy demads become internal parameters determined by macroeconomic growth and by conservation (both autommous and price-driven). Capital accumulation and economic growth are affected by changes in eners costs. Interfuel substitution and technologically-determined conservation lie within the domain of MARKAL.

\subsection{Organization of this repont}

Section 2 contains a more detailed descriptions of the MARKAL and MACRO models and the concaps underlying the linkage of the two modils. Section? summarizes some of the technical differities that had to be overcome. Section 4 describes the modeling language and users' support syste. Section 5 presents typical numerical results. 
2. MAHKAL, MACIRO and the linkage appronch

\subsection{The banic conceplo}

Figure I provides an overview of the connections between the two components of the aystem. To mimize the need for structural changes in the two original models, we have intraduced only two typo of linkage. There are physical flows of energy from MARKAL into MACRO, and there are energ coum payments from MACRO into MARKAL. This is much the same approach that has proven itseIn ETA-MACRO. The principal difference is that the physical nows of energy are defined here as "Uad Energy Demands". They are exogenous to the stand-alone version of MARKAL, but endopesous to the linked model. The costs of energy supply appeas in the objective function of MARKAL, but enter into MACRO through the period-by-periad constraints governing the allocation of the my's aggregate output between consumption, investment and energy cost payments.

The linkage between MARKAL and MACRO is based upon one key idea - the concept of an ecomay-wide production function. Just as with any other attempt at understanding the complexities of a exonomic system, there are pros and cons in adopting this particular abstraction. The principal adratage is that this enables us to make a direct link between a physical process analysis and a stamber long-lerm macroeronomic growth model. The principal disadvantage is that we cannot make a connection with the interindustry composition of demands (described, for example, in terms of two-pit SIC codes).

This is an intertemporal rather than a recursive system. Since savings and investment decision are modeled through the maximization of discounted utility, expectations affect the acculation of capital over time. Expectations also affect the optimal rate of depletion of exhaustible reanceses and the apeed of introduction of new technologies.

\section{MARKAL}

The MARKaL (MARKet ALlocation) model was developed between 1976 and 1981 as a muinational collaborative effort within the framework of the International Energy Agency. See Fidbane et al. (1983). MARKAL is a technologically oriented linear programming model of the enesg sector. The system boundaries are defined by the user. The model has been used for studies of the mational energy systems for most countries within the IEA. See Tosato et al. (1984). It has also ben wed to support energy planning in developing nations such as Brazil, China, Ecuador and Inmesia. It has been applied to regional energy systems in Canada and community energy planning in Sweden. See, respectively, Berger et al. (1987) and Wene (1989). 


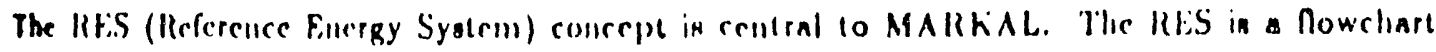
showin all posuible roulcs from cach source of primary encrgy through various tranaformation sleps to each ad-use demand ecelor. The nowchart can be extended to include emissions for each activity in which aergy is tranaported or converted from one form to another. MARKAL describes these routca, ence conversion and distribution technologics and various emissions control options. The model idents those routes and technologies that best satisfy the overall objectives of the energy. envimental system. The model describes the technical and economic propertiea of each technology - ad may also describe the technical and behavioral constraints upon their implementation. Typical paramen include energy efficiency, emissions, operating and maintenance costa, initial investment and milability factors.

The moat common formulation is to satisfy the end-use demands at a minimum present value of syem costs. Typically, the real annual discount rate lies between $4 \%$ and $8 \%$. The modeling borim in 25-40 years, usually described in time stepe of 5 years.

MARKAL is a data-driven model. The numerical results depend heavily upon the input assumetions. The logical structure is relatively simple. Most constraints describe annual, seasonal or diural energy balances. There are constraints ensuring that enough capacity will be built to meet the dem for secondary and tertiary energy carriers, and there are other constraints allowing for sched and unscheduled maintenance. The input dala can be grouped into four broad categories:

- Technology categorizations. The scale may be either large or small. Both price-induced and m-price conservation may be included in the definition of a technology. A typical large-scale unit mold be wo integrated coal-gasification combined-cycle electricity generating station. Heat pumpe and dretric cars are examples of small-scale end-use technologies. Conservation options might include doul-pane windows and high-efficiency oil burners. Technology characterizations represent most of the inat data wo MARKAL model.

- Sources of primary energy. Primary energy may be defined in terms of oil and gas wells, coal ad uranium mines, and biomass raw material. These sources are usually characterized by supply curm showing the annual potential supply and extraction costs. For exhaustible resources, there may be andaints indicating the cumulative total of proven reserves and additional resources that might be ava 3 we over the planning borizon. Import and export options are also included here.

- Useful energy demands. In the stand-alone version of MARKAL, end-use demands are spected exogenously for all time periods. The demands may be defined either in terms of energy requements or in terms of an energy service, e.g. vehicle-kilometers of automotive transport or tons of 


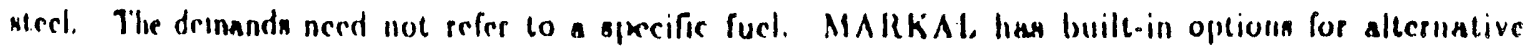
fucls and end-use utilization techinologies.

- Environmental constraints. Environmental constraints may be introduced as a physical cap on emissions such as sulfur dioxide, nitrogen oxides or carbon dioxide. The dual variables on these constrimle may be interpreted in tepms of emission fees of laxes.

In a lines programming model such as MARKAL, it is atraightforward to impose upper bound upon the level of a lectnology in a single period and upon the rate of growth between two perioch These are abeolute bounds and cannot be violated. In a nonlinear programming model, one can introduce "zoft" bounds - limits that may be violated but at progressively higher costs. Acconfingly, we have added a new feature to MARKAL: quadratic penalties for above-normal rates of market penetration. The user specifies a "normal" rate of growth for new tochnologies, and also specifia the quadratic penalty factor. This allows the model to simulate "crash" programs for rapid but atly rate of market penetration of new technologies. Through the nonlinear formulation, we smook the introduction rates, and avoid the rapid discontinues that otherwise lend to be observed in linear programming models. The new feature operates independently of MARKAL's absolute limits. These remain available to the user.

\subsection{MACRO}

The MACRO production function is characterized by smooth subetitution. With its nonlinear form, amall price change leads to a small change in the mix of inputs or outputs. The structure leads to paitatively different results from those generated by a lineas program such as MARKAL. With lines program, it is typical to observe "penny-switching" effects. That is, a small change in prices will bad either to no effect whatever - or else to a large change in the composition of inputs or outpets

The iagete to the production function consist of capital, labor and useful energy demands. Capital, labor and energy may each be substituted for the other, but there are diminishing returno to the sabstitution process. This is the way in which the model incorporates price-induced energy conervation. In addition, there is the possibility of autonomous improvements in energy efficiency (Aks, for short). These are non-price factors that could reduce energy demands per unit of gross outpace

To avid the econometric estimation of many parameters, the production function is a nested CES (constant elasticity of substitution) form. At the top level, there is a capital-labor aggregate that mag be substituted for an energy aggregate. At the bottom level, there is a unitary elasticity of 
sulsstitation between capital and lalerr, and the encrgy aggregate in separable. Thin atructure implies that emital and latbor may be substituted directly for each other, e.g. lhrough the automation of lalvorintemine tank. The higher the wage rale, the more altractive it becomes to adopt automation.

With this specific form of CES neating. price-induced conservation operates by lowering the margial productivity of capital and labor. That is, if there is a rise in energy costa, the production functio allows us to adapt by substituting more capital and labor in place of energy. This is also an indired way of allowing for behavioral reaponses such as lowering the thermostat in reaidential and commacial building.

In representing conservation within any model, there are two important guiding principles. The dexription should be inclusive but avoid double counting. Further, the representation should be tranaperent. It should be easy to communicate whatever assumptions are made about saturation effects of specific conservation technologies. MACRO has a built-in mechanism that ensures transperency. Most MARKAL data bases contain considerable engineering information about consermation, but the information is usually not inclusive. Moreover, because of the tichness of techadogical representations, it may be difricult to convey the meaning of model results to decision makes In the future, it will be important to develop model procedures that retain the conservation information contained within MARKAL, but avoid double counting when this data base is linked to MACIO.

Each calegory of useful energy demands may be substituted for the other. In effect, we assume "want independence" between them. See Frisch (1959). The ease or diffuculty of price-induced conservation is governed largely by the value adopted for ESUB (the elasticity of substitution between the end and the capital-labor aggregates). In the present version of MARKAL-MACRO, we bave not atempted to distinguish between short and long-run price elasticities of demand. As a result, there an be discontinuities in the demands between the base year of 1990 and the first projection year of isca The model is designed for long- rather than short-run analysis.

The economy's long-term growth rate is determined primarily by the value assumed for the gromth of the labor force and its productivity. The combination of these two factors is described in labor "efliciency units". For shorthand, this is the "potential" growth rate of the economy. It is a majo dẹterminant of the utility discount rate employed in the MACRO objective function. If there is a rive in energy costs, it will be optimal to reduce consumption and investment. With a drop in capital formation, the realized growth rate will then fall short of the potential. 
3. The eprocific of hardlinting

\subsection{Beact:marking the model (calibration)}

The MACRO production function containe a capital-labor term and an energy aggregate. The usep apecify an overall elasticity of substitution between capital-labor and energy. Each of the uscful mergy demands enter as inputs into the energy aggregale. Thus, benchmarking involves the eatimaio of a coefficient for the capital-labor term and for the 23 components in the energy aggreque.

To calibrate the MACRO submodel, the following 1990 base year data are required: GDP, aggreple energy coats, the demand and the "reference" price for each category of ugeful energy. Estimen must also be provided for the capital-GDP ratio, the depreciation rate, and capital's value share GDP. The three latter parameters must be consistent with the net rate of return on capital that is assumed in the stand-alone version of MARKAL.

The calibration procedure gives the modeler some degrees of freedom, but it also requires careft attention to the logical consistency of the base year data. The linked model requires estimates of bae year economic activities such as the energy system's total capital charges and operating costs. It ab requires an estimate of the investment levels, import costs and export revenues. The GDP is readiy available from standard statistical sources. The base year useful energy demands may be taken from the stand-alone version of MARKAL.

The user must be careful in determining the reference prices needed for calibrating the prodation function. If prices were to remain constant at these levels, energy demands would coincide with the GDP growth rate less the AEEI value. In principle, the reference prices should be identical with the nndiscounted marginal costs (also known as shadow prices) taken from the dual solution to the rogramming model. In practice, however, it is typical for the primal solution to be overtearmined by the requirements for statistical consistency with base year production and conemption estimates. The supply and demand curves are both vertical at this point. (In technical langese the primal solution is said to be "degenerate", and the dual solution is therefore inddaminate.) As a rough-and-ready shortcut, we have therefore employed the 1995 rather than the 1991 shodow prices for benchmarking purposes.

To illustrate this calibration procedure, Table 1 lists the values of the useful energy demands thas ane employed as exogenous inputs to MARKAL. It indicates the values of these demands in the bace year (1990) and in the terminal year (2030). For 1990, the MARKAL-MACRO demands are fixed to aixide with those in MARKAL, but in 2030 the demands may differ because of price-induced 
sulsalitution and alno because of energy-economy ferdbacks.

Ueeful energy demands are decoupled from GDP growth by paramelere that ara termed the AEEl (wlonomous energy efficicney improvement) rate. These decoupling factore represent a varicly of nemprice variable that affect uscful energy demands. Examples include: nonunitary income elasticitio of consumer demand, saluration phenomena and long-term changes in interindustry compation. There may be new sources of energy demands such as an increace in the quantity of electricity required for electronic computers in the home and office. For example, the analyat needs to have the option of projecting a slowdown in population growth rates, and therefore a decoupling betweating needs and aggregate income growth. At the same time, the growth of air transport may be bigher than that of the economy as a whole. The inlegrated model is designed so that these base (o potential) growth rates are subject to modification as a result of price-induced conservation and cargy-economy feedbacks.

To estimate the AEEI decoupling rates empirically, we have tried to be consistent with the useful energy demand projections employed in MARKAL. According to Table 1 , the annual MARKAL growth rate for category RO (residential space heat), is only $0.9 \%$ between 1990 and 2030 - even though the GDP growth rate is projected at an average of $2.0 \%$. Accordingly, we take take the AEEI for caicgory $\mathrm{RO}$ to be $2.0 \cdot 0.9=1.1 \%$.

For most of the 23 end-uses, this procedure leads to a positive value of the AEEI. There are only three categories ( R2, R9 and T4 - residential cooling, commercial miscellaneous appliances and air trasport, respectively) where the MARKAL end-use demand growth rate exceeds that of the GDP. In the cases, we impute a negative value to the AEEI. This is by no mean a satiofactory way to allow for new wes of energy, but it provides a starting-point for a productive dialogue between the adrocates of top-down and of bottom-up approaches to energy analysis.

To summarize: The MACRO submodel requires only modest amounts of data in sddition to there that are normally required for MARKAL. The additional data requirements include the followisg: base year GDP; potential GDP growth rates; initial capital-output ratio; aggregate depreciation rate; and the elasticity of substitution between capital-labor and useful energy demands. All other elements of the linked model may be deduced either directly or indirectly from these parameters. E.g., capital's initial value share of the GDP may be determined from the capital-output ratio, the depreciation rate and the net return on capital that is employed in the stand-alone version of MARKAL. 
Table I. Uocful energy demand projectionn employed in MAltKAL

Uecful energy demand calcgory

RO Residential space heating

RI Residential water heating

R2 Residential cooling

R3 Residential lighting and appliances Subtotal, reaidential

R5 Commercial space beating

R6 Commercial water beating

R7 Commercial cooling

R8 Commercial light

R9

Commercial miscellaneous appliances Subtotal, commercial

$\begin{array}{ll}\text { T0 } & \text { Automobile } \\ \text { T1 } & \text { Light truck } \\ \text { T2 } & \text { Heavy truck } \\ \text { T3 } & \text { Bus } \\ \text { T4 } & \text { Air } \\ \text { T5 } & \text { Ship } \\ \text { T6 } & \text { Rail } \\ \text { TX } & \text { Military air } \\ & \quad \text { Subtotal, transport } \\ & \\ \text { I1 } & \text { Iron and steel } \\ \text { IA } & \text { Aluminum } \\ \text { ID } & \text { Industrial boilers } \\ \text { ID } & \text { Fabrication and electric drive } \\ \text { IH } & \text { Other industrial heat } \\ & \text { Subtotal, industrial } \\ & \\ \text { NY } & \text { Non-energy demands }\end{array}$

Total useful energy demands
1990

$$
\text { (exajoules) }
$$

4.04

1.10

1.37

2.26

8.77

2.48

0.12

2.77

1.21

0.95

7.53

8.63

2.58

5.06

0.14

2.73

1.25

0.54

0.58

21.52

0.80

0.32

4.39

2.51

4.82

12.84

1.15

51.81
5.78

1.57

4.13

4.98

16.47

4.97

0.24

5.54

2.42

2.17

15.34

12.86

3.85

11.18

0.23

11.97

2.75

1.20

0.58

44.61

0.80

0.70

9.69

5.54

10.67

27.38

2.54

106.34
2.00

1.81

annual growth rale, $\%$

0.90

0.90

2.80

2.00

1.59

1.75

1.75

1.75

1.75

2.10

1.80

1.00

1.00

2.00

1.30

3.76

2.00

2.00

0.00

1.84

0.00

2.00

2.00

2.00

2.00

1.91 


\subsection{Trealment of capilal chargra and residual enpacitico}

In earlier applications, the MARKAL and MACRO submodels differed in their terminal conditios and in their treatment of capilal charges. MARKAL views investments as one-time expendures that provide a stresm of capacities available during subeequent time periods. If a capital investant aurvives past the horizon dale, it receives a salvage credit during the lerminal period. This is condimes said to be a "dual" terminal condition.

By contrast, MACRO employs a primal terminal condition. That is, the rate of investment in the find period muat be large enough to allow post-horizon growth to proceed a a constant geometric rate. MACRO allows for investment costs through capital recovery factors - with a uniform annual amorfation charge throughout the useful life of plant and equipment. No salvage values are assigned to the atocks of oil, gas, plutonium and other resources available for use during the post-terminal perial To reduce horizon effects in the linked model, we adopted the MACRO conventions for posthoriz growth and for investment costs. Incidentally, even before the merger, both models were using the idatical numerical value of the discount rate for investment purposes $-5 \%$ annually as the real cost capital (net of inflation) to the U.S. economy.

MARKAL and MACRO both provide for the durability of capital goods, but each in a somental different way. In MARKAL, there is a fixed value assigned to the useful life of each distinct techmogy, and there is a uniform amount of capacity available from that investment during each year of its lfe span. There is an explicit distinction between the decision variables that govern investment and that govern the use of capacity. In MACRO, this distinction is not drawn; depreciation is view a a geometric decay process - typically a decay rate of $5 \%$ annually. This reduces the numb of decision variables and constraints and therefore reduces the time required for computations, but means that we do not have the option of abandoning exceas capacity in the form of obsolete capit equipment. In the linked model, we follow the original MARKAL formulation for the energy sectar and follow the MACRO formulation for the economy-wide capital stock.

In the stand-alone version of MARKAL, there is no reason to impute capital charges to "resimal" capacities (i.e., those remaining from pre-1990 investment activities). For purposes of the linked model, however, it is essential to provide consistent year-to-year accounting for the energy secter capital and operating costs. We therefore apply capital recovery charges to these residual capailiea - just as in the case of new facilities. 


\section{J Pull ve. differential conting}

The atand-slone version of MARKAL is demand-driven. The useful encrgy demands are provided as inpuls. In the linked model, useful energy supplies, demands and prices are interdependent. They are determined jointly by MARKAL and MACRO. Aggregate energy costs (hercalter abbreviated EC) are generated in MARKAL. Along with aggregate consumption ani investaent, the EC variable represents claime upon the gross output generated by the MACRO production function. EC includes the capital charges, operation and maintenance, and fuel costs for all supply and convernion technologies.

One must be careful in defining the remaining energy costs reflecting end-use demands. Cleart, al fuel coste are included in EC, but not all capital and operating coats. The "final" users of energ (both consumers and producers) consume energy as part of a larger end-use. Gasoline is used to provide transportation. Fuel oil, natural gas and electricity are purchased to provide space heat as part a comfortable building environment. Boiler fuels for process heat and electricity for electric drives are used as an input in the production of industrial products and services. However, the capital costs of automobiles, highways and other transportation infrastructure are not normally viewed as energy sector costs. Similarly, the energy sector does not include the land, buildings, furniture and equipenent for buildings. It does not include the general facilities and equipment employed in the manuacturing sector. Outside the energy sector, MARKAL includes only the additional expenditures required for unconventional alternatives. It includes the incremental costs of CNG vs. gasoline-fueled vehicher of oil ve. resistance heat vs. heat pumps for space heat; of process heat from cogeneration vs. direc generation of process heat for manufacturing. In each of these casen, MARKAL excludes the capith operating and mantenance costs for a baseline technolozy, and includes only the additional costerequired for the unconventional alternatives.

This convention is consistent with the view that MARKAL is primarily an energy sector modd An alternative device is chosen whenever a useful energy demand can be met at a lower cost by that device than by the existing technology. If the total cost of providing end-use services were indaded in the definition of energy costs, virtually the entire GNP would be attributed to the energy sectar. By defining EC to include only the differential costs, we focus upon the fuel component. In chooing between alternative technologies, it is the cost difference that determines the winner, not the abeokite coat kvel of the baseline technology. If we had included the absolute levels of all end-use couth, we would have extended MARKAL far beyond the conventional boundaries it the energy sector, and would have distorted the feedback relationshipe with the MACRO portion of the combined model. 
Even il the definition of EC, liad Iren ronstrained to include only nutomobilm and enregy-using equipinemt, thete would lave been a disproportionate impact upon the non-encrgy sectors of the cconomy.

\section{Promoting model uability}

\subsection{GAMS and MUSS}

To incorporate nonlinearities in the constraints and objective function, MARKAL-MACRO is writte in GAMS (s generalized algebraic modeling aystem). See Brooke et a. (1988). Data-base managenent and acenario comparisons are handled through a user-friendly interface known as MUSS (MARIAL Users Support System). See Goldstein (1991). Through MUSS, the user can modify the individaal MARKAL tables provided in their traditional OMNI format. The inlerface then translates these tables into a form that can be recognized by GAMS. It also bandles the additional data required for the MACRO submodel and for the quadratic penalties associated with rapid rates of market penetration.

\subsection{Modeling language and optimizer (GAMS/MINOS)}

GAMS is a computer language specifically designed to facilitate the development of algebraic modek The syatax closely resembles the row-oriented style of formulating constraint equations. The MARRAL-MACRO wurce code is written in GAMS, but has been organized so that MACRO is largety isolated from the MARKAL submodel. This facilitates revisions in model structure.

GAMS provides a convenient interface to nonlinear optimizers, including MINOS (a model incore conlinear optimization system). MINOS handles nonlinear objective functions and nonlinear conetraints. These are parsed by GAMS so that the user does not need to write down the gradients associaled with the objective function and constraints.

With the U.S. MARKAL-MACRO data set analyzed in this report (4500 constraint rows), we come doce to the practical limits of the 1992 family of personal computers. On a 486/50-PC, it can take tree and a halr hours for a "cold start", but restarts typically require only $30-45$ minutes.

Each version of the model is controlled by dats provided to GAMS in the form of SETs and PARAMETERa. For MARKAL-MACRO, the SET: characterize the energy system by identifying the demad devices, energy carriers, etc. The PARAMETERs (oflen tables) provide specific information on infividual fuels and technologies, e.g. the unit costs, conversion efficiencies and market penetration 
limits. An imprortant fenture of (iANSS in ita domain clucking capabilities. Tlicece ensure that all the elements of PARAMFTERs and TABLEs fall within the acope defined by the source code's declarmions. This helps to identify errors in the input dala, e.g. A fucl inpul to nonexistent lochnolegy.

\subsection{Model users' wpport syolcm (MUSS)}

With any large and complex model, it is essential to provide the policy analyat with a model enviroment shell. Numerous runs must be made under a variety of technical and economic assumptions. Database handling errors are inevitable, but they can be reduced to a minimum if we employ a aystematic approach. As shown in Figure 2, MARKAL-MACRO is part of an integrated modeling aystem that encompassea the models, optimizers, scenario and data management, problem restart Landling, sensitivity analysis, and comparative analysis of results through color graphics.

The heart of this environment shell is MUSS. It is a system incorporating the features of a relational database, spreadsheet, file manager, and graphics presentation system. (See Figure 3.) MUSS enhances the productivity of the policy analyst. It enables the user to employ the identical databuse, and to switch between the original OMNI version of MARKAL, the GAMS version of MARIAL and the GAMS version of MARKAL-MACRO. At some future date, it is possible that there will be an OMNI version of MARKALMACRO.

MUSS employs pop-up menus, online context-sensitive help, pick lists and browse capability. These falitate the beation and modification of all numerical input data. The system also provides copy/detete macro commands to assist with standard adjustments to the database, e.g. addin/removing a lochnology. In the absence of this type of shell, any modification entails a series of error-prose dats entry steps. MUSS also includes a Reference Energy System drawing capability.

Data are managed by scenarios. Typically, a reference case is developed and then a series of sensitivity analyses, eg. alternative rates of market penetration for renewable technologies. For each of these scenarios, alternative cases may be run, e.g. examining the effect of imposing alternative $\mathrm{CO} 2$ reduction limits. The user assigns specific names to these scenarios/cases. These determine the names of the files passed to/from MARKAL-MACRO, and they control the access of MUSS to the input data and reathe Throughout, the user is provided with dynamic feedback into the dats "dictionary". In this way, there is immediate access to the name and characteristics of each technology in each time periol

MUSS provides a convenient way to analyze model results. It facilitates the retrieval of a desired subeet of results, and compares the information obtained from alternative cases. The results 
are organized into tables which are automatically ordered so as provide side-by-side comparison of a single result, e.g., the capacity of light water nuclear reactors, over a set of cases.

Graphs are generated through menus. The analyst places the cursor a a desired line and presses a single key. When examining a single technology, for example, both the capacity level and the associated "reduced costs" can be displayed on a single diagram. This provides an indication of economic attractiveness. Another standard plotting option allows for the display of activity levels of up to 50 technologies from multiple cases for a single year.

In addition to managing the interpretation of model results, MUSS allows the user to combine and reorganize information into custom graph tables. The results may be graphed as bar charts, cumulative bar charts, percentage (pie) charts, etc. Figures 4 - 21 were generated by MUSS. 
5. Model renulie

\subsection{Throc ecenariou}

To exercise MARKAL-MACRO, three alternatives were defined: a base case and two carbon emissie control ecenarios. The base case is intended as an extrapolation of current practices and policia It is one in which we are cautious on the prospects for the introduction of new supply and conservation technologies into the market place. This should not be confused with an "economic potential" scenario - one that indicates what could happen if each coot-effective supply and conservation technology were pushed to its limits. To the extent that MARKAL overstates the perforance of any of the new technologiea - or understates the barriers to their implementation auch a scenario would have built-in tendencies toward over-optimism.

The second scenario is one in which there is a deferred $\mathrm{CO} 2$ emissions constraint. Controls are deferrad until 2010. From that point onward, emissions are reduced to a level $20 \%$ lower than they were -1990 . This type of scenario is broadly consistent with the consensus position of 48 countries partiopating in the Toronto Conference of June 1988. According to Abrahamson (1989), the goal was descried as a $20 \%$ reduction in $\mathrm{CO} 2$ emissions by 2005 . Our scenario defers the initiation of controls by five years. This provides a period for adjustment so that newer and less expensive control options may le adopted. The implementation delay also allows the participating countries more time to reach agreasceat as to appropriate participatory roles.

The third scenario is one in which there is a cumulative $\mathrm{CO} 2$ emissions constraint. It is desiged to avoid the potentially disruptive effects of imposing controls abruptly in 2010 . This scenaio accepts the same overall goals as the deferred constraint case. Cumulative emissions are redued by the same total quantity as in the deferred case. Annual emissions in 2030 are limited to the idential quantity. The impact on global climate would be virtually indistinguishable. With this scenario, there is the nexibility to introduce emission control technologies at either an earlier or a later date than 2010, and this flexibility helps to reduce GDP losses.

It is assumed that the international crude oil price is identical in all three scenarios. The price was 200 per barrel in 1990. Thereafter, as a result of the exhaustion of domestic and international resoncen, the price rises gradually. It follows a "surprise-free" pach, reaching $\$ 31$ per barrel in 2010 and $\boldsymbol{H A}$ in 2030 . Given this oil price perspective, there is a built-in incentive for conservation and for the drebopment of unconventional energy resourcea. 


\section{2 mpact on the energy nystein}

Figure 4 shows the composition of primary encrgy consumption in the base casc. Total primen encrgy use increases throughout the 40 -yenp planning horizon at the annual rate of $1.12 x$. Each d the foasil fuelo grows less rapidly than the total - coal at an even slower rate than oil and gan. Nuclea energy declines through 2015, but rises quite rapidly thereafter. The contribution of renewalles rises continuously. For the period as a whole, its compound annual growth rate is 3.14\%.

Figure 5 compares all three scenarios with respect to the composition of energy consumption. In bou $\mathrm{CO} 2$ control scenarios, there is assive amount of price-induced coneervation. In 2030, the lotal i 20\% lower than in the base case. In the deferred case, consumption rises alightly before 2010, show a aboolute decline in that year, but growth is resumed thereaner. In the cumulative case, there is a dadine in 1995, but a gradual rise thereafer. The 1995 decline should not be taken too literally. This a direct effect of the failure to distinguish between short and long-run price elasticities of demand Had this distinction been introduced into the model, it is likely that there would have been even gater gains from the cumulative rather than the deferred scenario for emission controls.

By contrast with the base case, coal use drops sharply under both $\mathrm{CO} 2$ control scenarios. It falls $*$ an erratic rate in the deferred case, but smoothly when the constraints are cumulative. During the end decades, oil is the "swing fuel". In the base case, oil consumption increases steadily. By contrach in the deferred case, oil use increases slightly until 2005, drops sharply in 2010, and increases theres. With the cumulative constraint, oil consumption drope in 1995, and it increases gradually therener. Natural gan, nuclear and renewable energy consumption are almoet identical acroes all acenaim in all time periods. Their valuea are determined largely by exogenous upper bounds.

The nseful energy demands (UED) are of particular interest. These are determined endogenously through the interaction of the MARKAL and the MACRO submodels. They are directly affectal by price-induced conservation. Figure 6 compares total useful energy demands across all sectom of the economy. Under both emissions control scenarios, demands are lower than in the base case 1y 2030, there is an $18 \%$ overall reduction. Although the end result is similar, the path toward this muction differs considerably. Energy consumption rises smoothly with the cumulative $\mathrm{CO} 2$ constint, but it follows a zig-zag path in order to accommodate the year-by-year $\mathrm{CO} 2$ requirements of the deared case. There is a sharp drop between 2005 and 2010, and this leads to significant costs of adjutmenh Figure 6 ahows the importance of a long-term perspective. By starting early loward a give pol, we follow amooth pathe. This contrasts sharply with the distuptive effect of waiting until 2010 we impose controk. 
Through a close comparison of Figuren 5 and 6 , we call sec llint there in more rapid gruwth of UED than of lolal primary encrgy consmmption. Ao a fraction of primary encrgy inpule, the UED were $57 \%$ in 1990 . By 2030, the fraction increases to $77 \%$ in the base case and $1080 \%$ in both of the $\mathrm{CO} 2$ control scenarioa.

Energy intensities are compared in Figures 7 and 8. All three scenarios are characterized by reduction in the overall energy-GDP ratio throughout the planning horizon. This generalization holde both for primary consumption and for the UED. Price-induced conservation leads to greater reductione in the control cenarios than in the base case. The emiavion reduction goals are achieved partly through awitching away from fossil toward carbon-free fuels, and partly by using less energy to satisfy the end ne demanda.

Figure 9 indicates the overall contributions of electricity to the energy system. In all three scenarion, electricity rises at a slower rate than the GDP. Over the 40-year horizon, it grows $1.43 \%$ annually in the base case and $.85 \%$ when constraints are imposed on $\mathrm{CO} 2$ emissions. Figure 10 compares the source of electricity generation in 2030 . The sharp reduction in coal-fired electricity generation accounts for virtually all of the difference between the base and the control scenarios.

\subsection{Inpect on carbon emissions}

Carbon emisaions are compared in Figure 11. There are large differences between the base case and the two control scenarion. In part, these can be traced to price-induced conservation and in part to change in the fuel mix. According to the base case, emissions will increase throughout the planning horison. They are 20\% higher in 2030 than in 1990. By contrast, both control scenarios end up with a 20\% reduction from the 1990 level. Carbon emissions are closely correlated with total primary energy consumption and with UED. There is a smooth path in the base case and in the cumulative scenario. With the deferred scenario, there is an abrupt reduction between 2005 and 2010.

\section{4 lapect on the coonomy}

The macroeconomic variables (GDP, investment, consumption and energy costs) are all lower under the constrained scenarios than in the base case. Of the four, total energy supply costs are the mot remitive to the differences between the control scenarios and the base case. (See Figure 12). Figure 13-16 express the differences in terms of dollar costs. By 2030, the cost of imposing CO2 constraints amounts to a GDP loss of \$210-220 billions. The differences appear large when expressed in abolute dollar amounts, smaller when expressed as a percentage of GDP, and still smaller when expresed in lerms of differences in growth rates. At first glance, this appears paradoxical, but there is 
Table 2

Annual percentage growth rates, $1990-2030$

Macroeconomic indicalor

GDP

Consumption

Investment

Energy costo
Basc case

2.07

2.10

1.92

1.69
Conatrained cases Reduction

2.03

0.04

2.07

1.78

1.22
0.02

0.14

0.47 
- erady explanation. The criergy sector iepreacilts only about 10 of the cronomy a whole. When GDP in the divisor, virtunlly any scctoral magnitude appears small. Moreover, the encrgy-economy feedbats are not large enough to lead to major differences in growth rates. See Table 2.

MARKALMACRO generates the energy prices required 0 as to equilibrate uneful energy deman witb the least-cost mix of available supply technologies. There is one such price for each of the 23 meful energy demands in each year. Figures $17-20$ provide typical price series. These refer, respectively, to the residential, commercial, transportation and industrial sectors. Although the yearlo-yea percentage changes are not identical, the pattern is similar. Base case energy prices rise moderdely throughout the time horizon. These trends are a direct consequence of assuming a aystemalic increase in international oil prices. Higher cost technologies are then needed in order to meet the incresses in energy demands.

Under the two control scenarios, prices rise much more rapidly than in the base case. This provide an additional incentive for priceinduced conservation. Prices follow the patterns that are characteristic of the three scenarios. The paths are smooth in the base case and in the cumulative contrd scenario. They exhibit an abrupt increase when controls are deferred until 2010. From that date onward, the prices in both control scenarios converge toward similar values in 2030.

Figure 21 shows the shadow prices (implicit values) of the carbon emission constraints. These represent the incremental cost of further reductions in $\mathrm{CO} 2$ emissions. If all reductions are to be achiened through the taxation of carbon, these can be interpreted as the year-by-year tax level required in ade to meet the emissions targets. With the deferred controls scenario, prices remain zero through 2005 and then rise sharply in 2010. With the cumulative constraint, there is a positive value in 1995, and the price rises gradually over time. The compound annual growth rate is consistent with the magial productivity of capital throughout the economy - about $5 \%$ annually. In both control sceariog, the price reaches $\$ 270$ in 2030 . In this version of MARKAL, there are no "backstop" lechalogiea - and therefore no upper bound on the price of carbon.

Caveat: Most of these economic impacts may be interpreted as the direct consequences of the iurut assumptions with respect to supplies, demands and emissions control scenarios. If we are sure that we will eventually bave to impose emissions controls, it is preferable to start carly, and to adopt a smoch transition strategy. With certainty on the imposition of controls, the cumulative case is clearly preliable to the deferred case. With uncertainty, however, it may be preferable to adopt a hedging straleg baed upon an explicitly probabilistic decision analysis framework. These three scenarios reprecent a useful beginning in that direction, but do not in themselves determine an optimal hedging stratiog. 
6. concluding nole

The three ecenarios are nol sumicient to validale MIARKAL-MAC.RO, but they do indicate that the mode exhibile plausible behavior. By contrast with a aland-alone engincering model, uacful energy demand are reduced in response to higher energy prices. Carbon emisoion constraints lead to lower GDP, imestment, consumption and energy supply costa. The quantities and timing can be compared for different policy options, and the price structure indicates the stresses that might be entailed by the imposition of $\mathrm{CO} 2$ controls. It is particularly useful to Le able to identify those strategies that might lead to mooth rather than difficult transitions.

This paper has demonstrated the feasibility of a formal hardlink between MARKAL (a systems engineriag model) and MACRO (a long-term macroeconomic growth model). The merger combines MACRO's aggregate view together with MARKAL's detailed analysis of technical options for the energy astem. The differences between the engineer's and the economist's perspectives are highlighted by the arrent discussion on conservation options and their role in controlling $\mathrm{CO} 2$ emissions. The experies from this demonstration is limited, but it indicates that MARKAL-MACRO provides tool to facitate dialogue between the engineer and the economist, and will also facilitate dialogue with policy makers. 
D.E. Abrahamson, 1989. "The Changing Atmasphere: Implications for Global Securily", Toronto Conference Statement, June 1988, in The Challenge of Clobal Warming, Island Press, Washiaglon, D.C..

S.d. Ahn, 1992. "MARKAL-MACRO/2 - An Encrgy-Environmental Modeling System", enginea's thesia, Department of Optrations Research, Stanford University.

R.G.D. Alien, 1968. Mocroeconomic Theory. Macmillan, New York.

C. Berger, A. Haurie, G Savard, R. Loulou, G. Lafrance and J.-P. Surprenant, 1987. "MEDiz-MARKAL: Un Couplage Entre Deux Modeles Techno-economiques du Systeme Energetique du Qudee" R.A.I.R.O. Recherche Operationelle, Vol.21, No 1.

A. Brooke, D. Kendrick and A. Meeraus, 1988, GAMS: A User'c Gride, Scientific Prese, Redwoed City, Calilornia.

S. Chakravarty, 1969. Capital and Dejelopment Planning, MIT Press, Cambridge.

R. Frisch, 1959. "A Complete Scheme for Computing All Direct and Cross Demand Elasticities in a Medel with Many Sectors", Econometrica, 27.

L.G. Fishbone, G. Giesen, G. Goldstein, H.A. Hymmen, K.J. Stocks, H. Vos, D. Wilde, R. Zolcher, C. Balzer, and H. Abilock, 1983. "User's Guide for MARKAL (BNL/KFA Version 2.0)", BNL 51701, Brookhaven National Laboratory, Upton, N.Y.11973 and Forschungsanlage KFA-Julich, D-5170 Julich

G.A Goldstein, 1991. "PC-MARKAL and the MARKAL Users Support System - User's Guide", BNL-46319, Brookhaven National Laboratory, Upton, N.Y. 11973.

K.C. Boffman and D.W. Jorgenson, 1977. "Economic and Technological Models for the Evaluation of Energy Policies", The Bell Journal of Economics, vol. 8, no. 12.

J. Jotnswon, O. Bjorkquist, C.-O. Wene, 1992. "Integrated Energy-Emissious Control Planning in the Community of Uppeala", International Jcurnal of Energy Research.

A.S. Manne and R.G. Richels, 1992. Buying Greenhouse Insarence: the Economic Costs of Carban Diozide Emissicin Limits, MIT Press, Cambridge.

A.J. Manne and C.-O. Wene, 1992. "MARKAL-MACRO: A Linked model for EnergyEconory Analysie", Brookhaven National Laboratory, BNL-47161.

W. Marcuse, L. Bodin, E. Cherniavsky, and Y. Sanborn, 1976. " Dynamic Time Dependent Moded for the Analysis of Alternative Energy Policies" in: K.B. Haley (editor), Operational Research '75, Narth Holland, Amsterdam.

M.D. Rowe and D. Hill (eds), 1989. "Estimsting National Costs of Controlling Emissions from the Eergy System, A Report of the Energy Technology Systems Analysis Project, International Energ Agency", BNL 52253, Brookhaven National Laboratory, Upton, NY 11973.

A. Svoronos, 1985. Drality Theory and Finite Boriza Approximations for Discrete Time Infiait Borizon Convex Programs, Department of Operations Research, Stanford Unjversity, April.

G. Tosato, J. Brady, P. Essam, M. Firnis, G. Gician, S. Rath-Nagel, B. Yos and D. Wilde, 1981 Energy Afler the Eighties, A Cooperative Study by the Countries of the IEA, Elsevier, Amstodam. 
C.-O. Wene, 1980. "The Optimum Mix of Conservalion and Sulmatitution: All example from Relrofilting Old Buildings", International Journal of Energy Rrscarch, Vol 4.

C.-O. Wene, 1989. "Using a Comprehenaive Moxtel for Communily Energy Planning", in: $l$. Lundquiat, L.G.Matlason and E.A.Eriksson (eds.) Spatial Energy Analysis - Models for Strategic Decisions in an Urban and Regional Conlert, Avebury, Aldershot.

S. Yasukawa, O. Salo, Y. Tadokoro, T. Nagano, II. Shiraki, T. Kajiyama, Y. Nakano, and Y. Shimoyamada, 1989. "Emisoion Control Analyois Using the MARKAL Model of the National Energy System of Jupan - Part II", in: M.D. Rowe and D. Hill (op. cit.). 
Figure 1

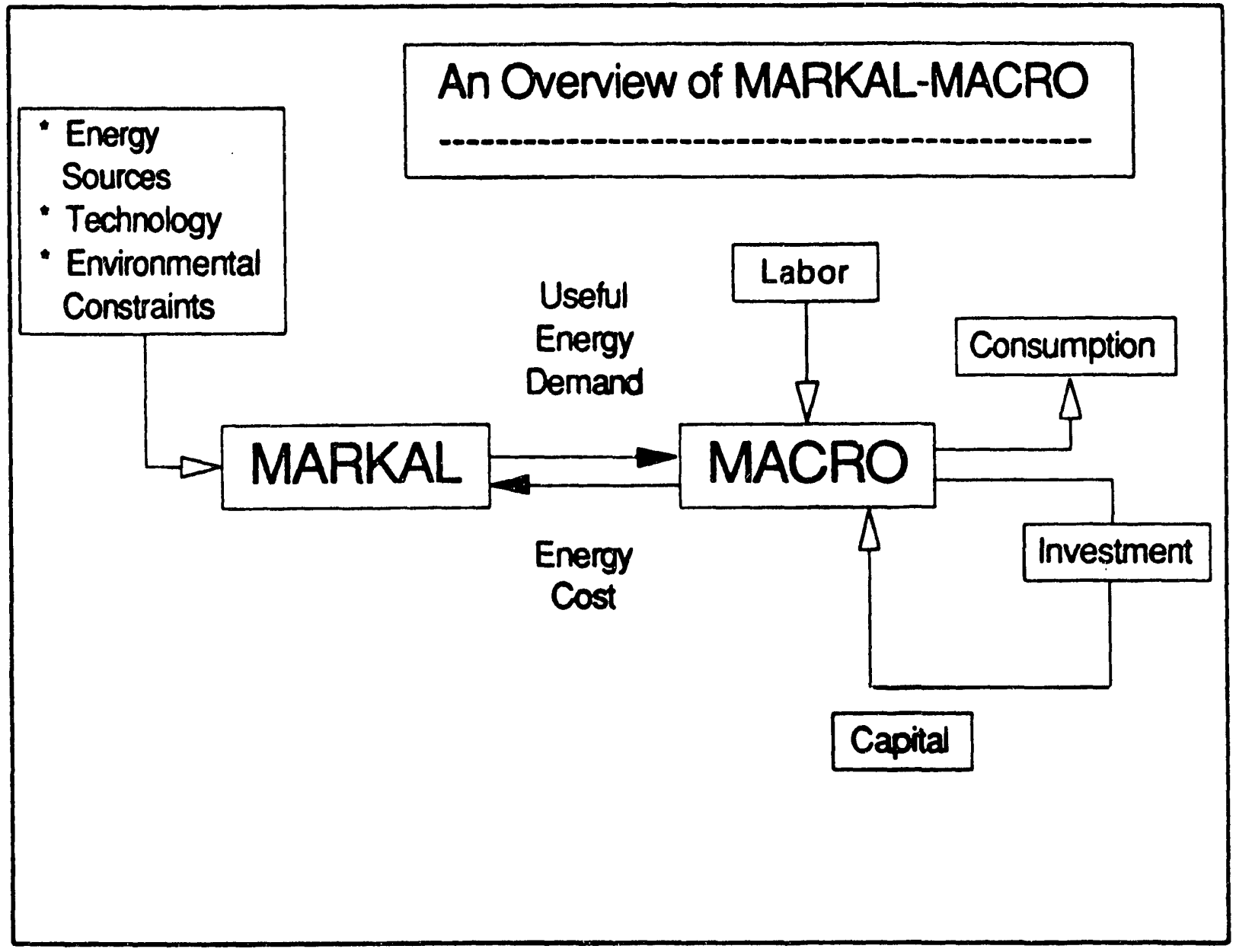


Figure 2

\section{MARKAL/MARKAL-MACRO USERS SUPPORT SYSTEM}

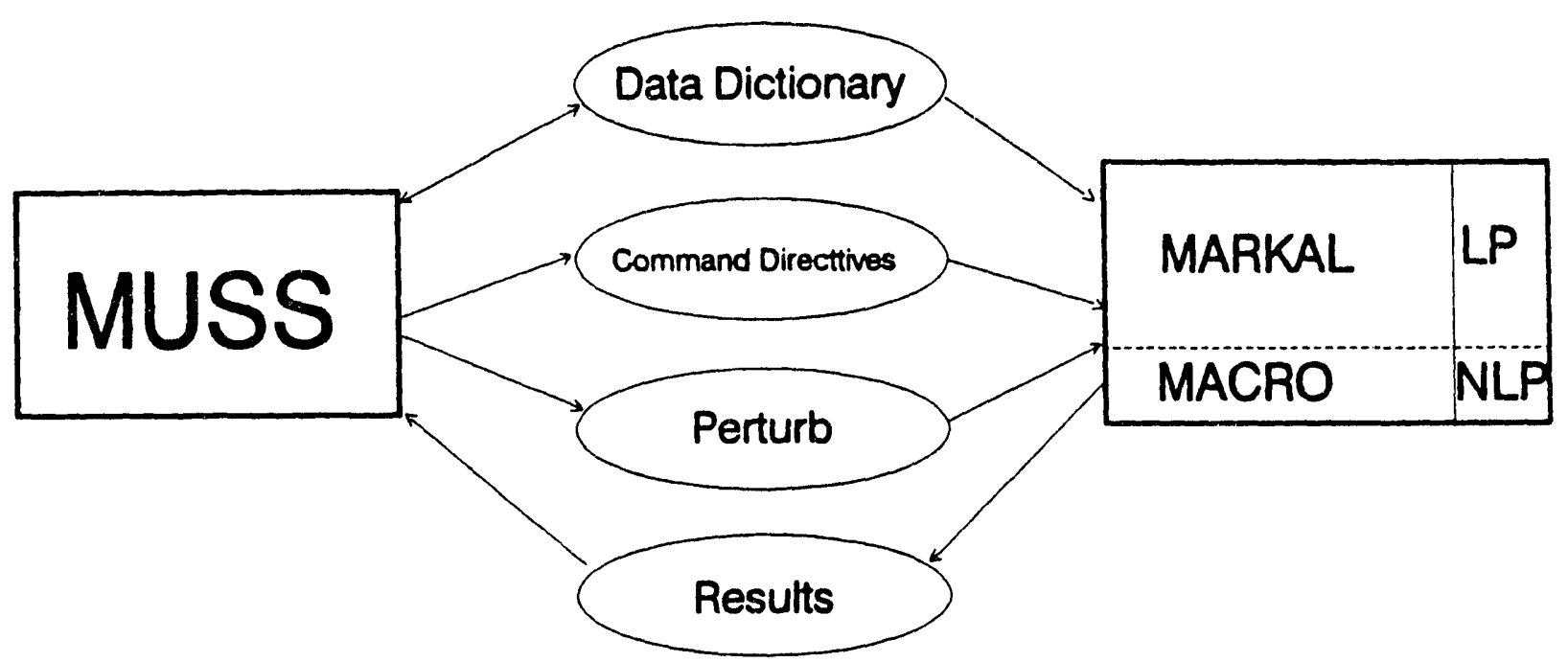


Figure 3

\section{CAPABILITIES OF MUSS}

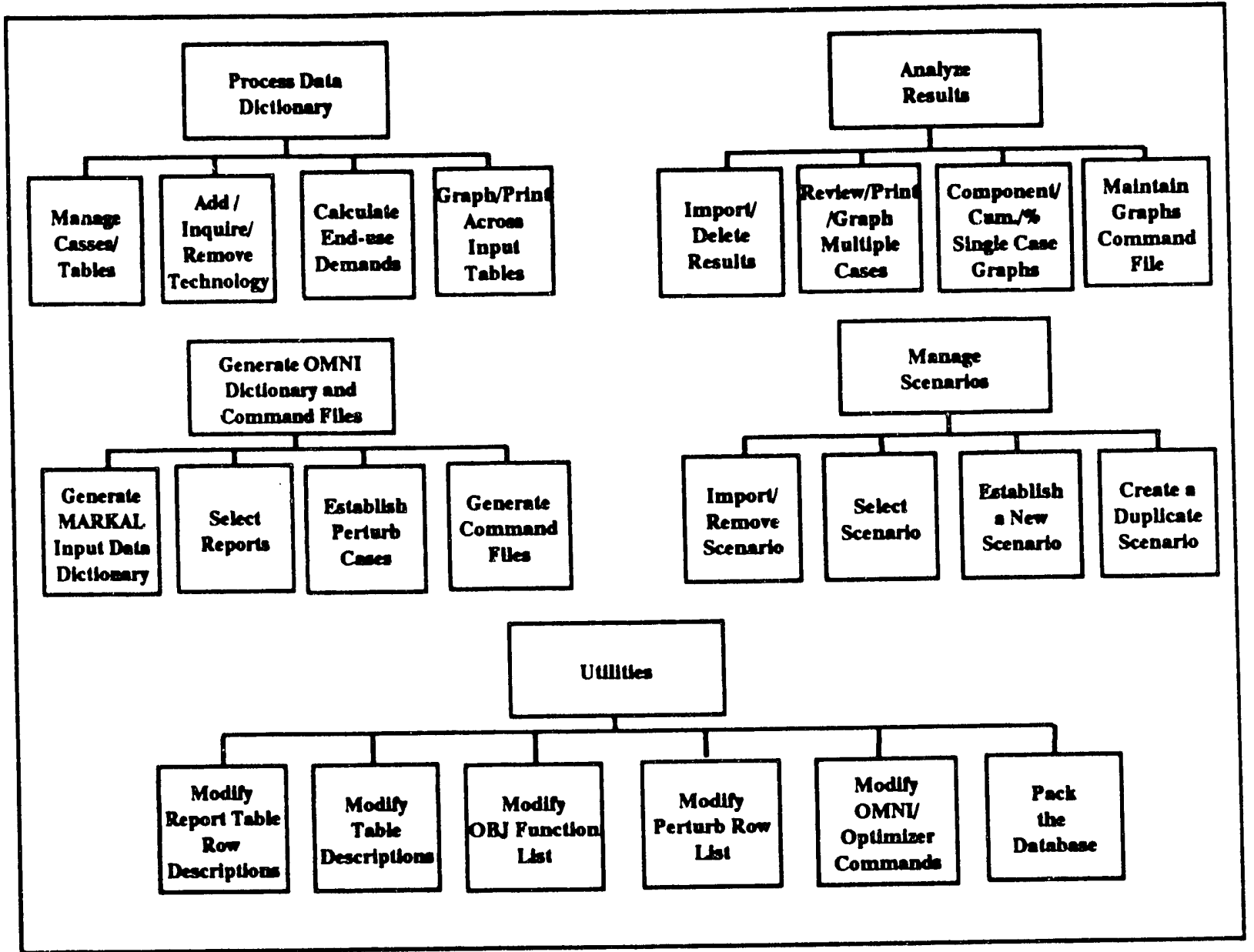

MUSS System Overview

The above diagram shows the actwities supported by each of the five main processing paths of the system. 
Figure 4

BASE CASE: PRIMARY ENERGY USE

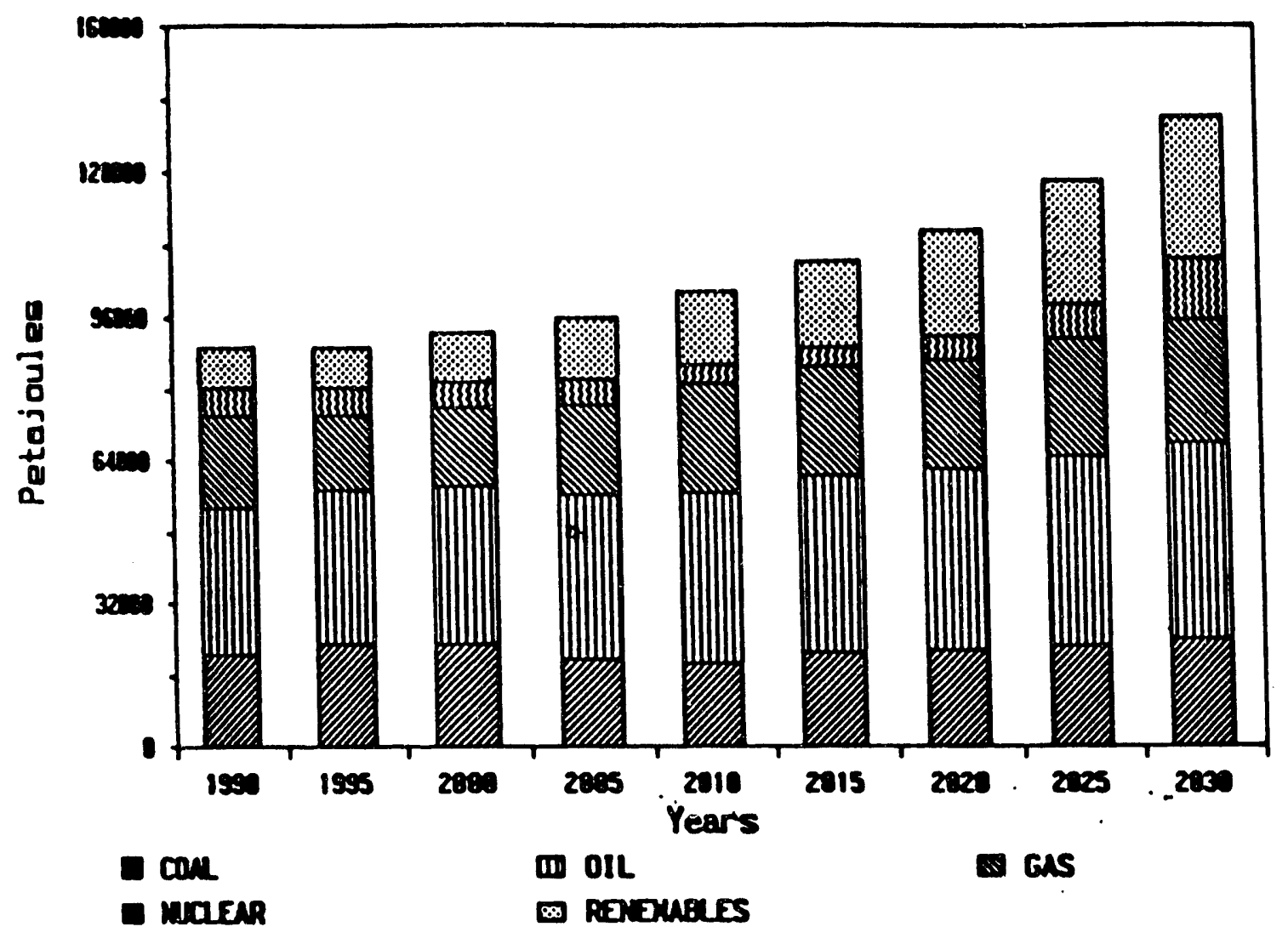


Figure 5

PRIMARY ENERGY USE IN EACH SCENARIO

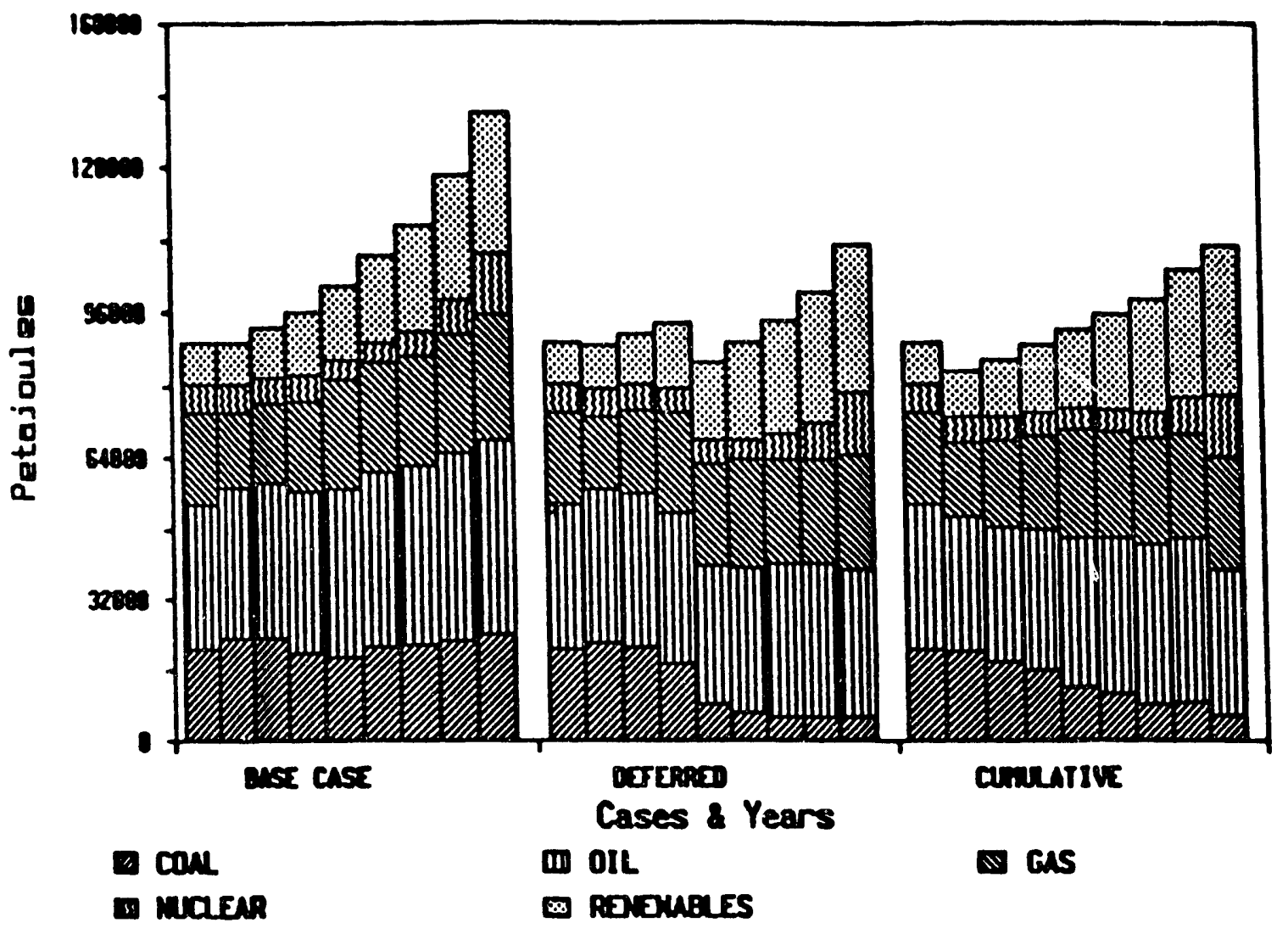


Figure 6

TOTAL USEFUL ENERGY DEMAND

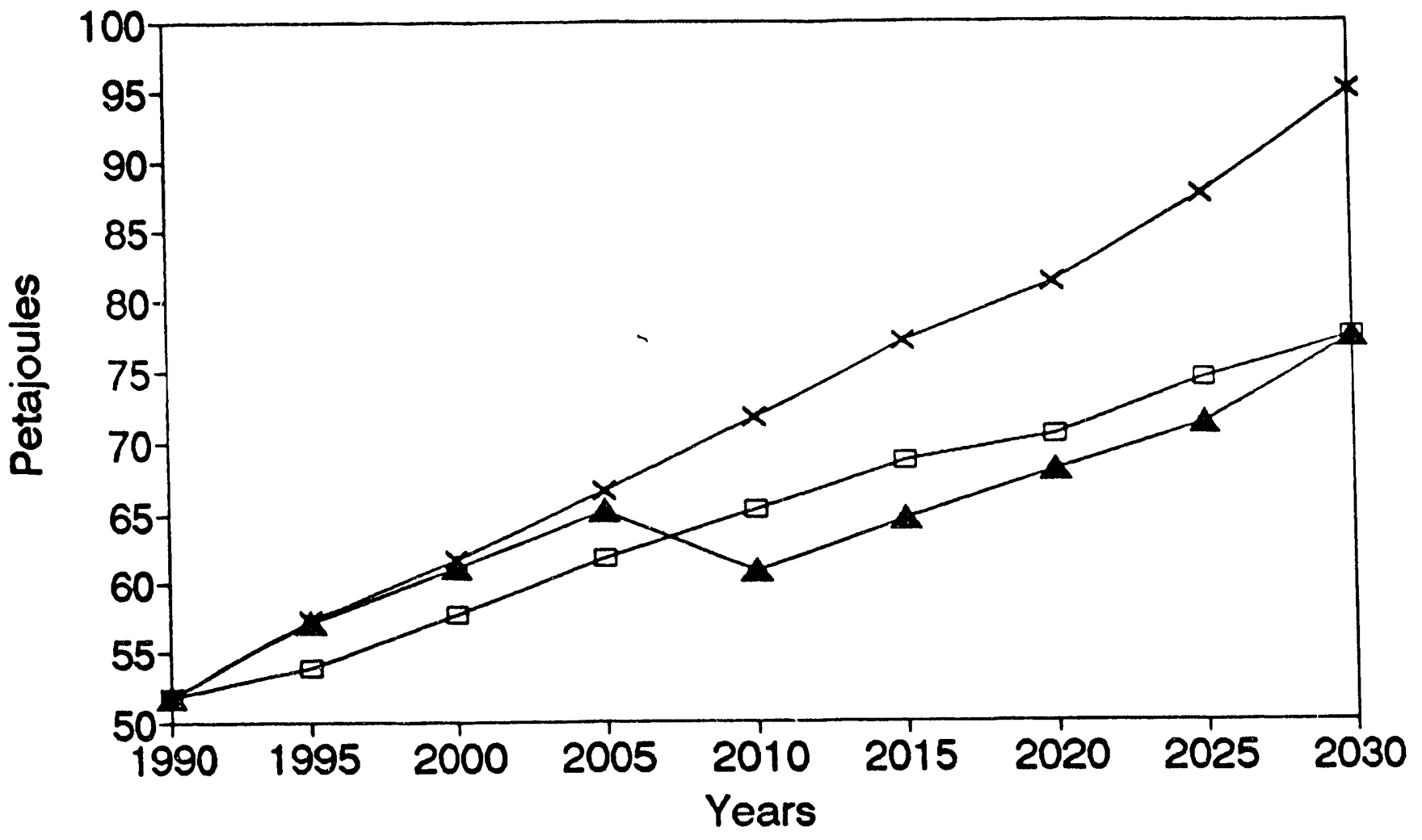

$\rightarrow$ Base Case $\leftarrow$ Deferred Case $\square$ Cumulative Case 
Figure 7

ENERGY INTENSITY: PRIMARY ENERGYIGDP

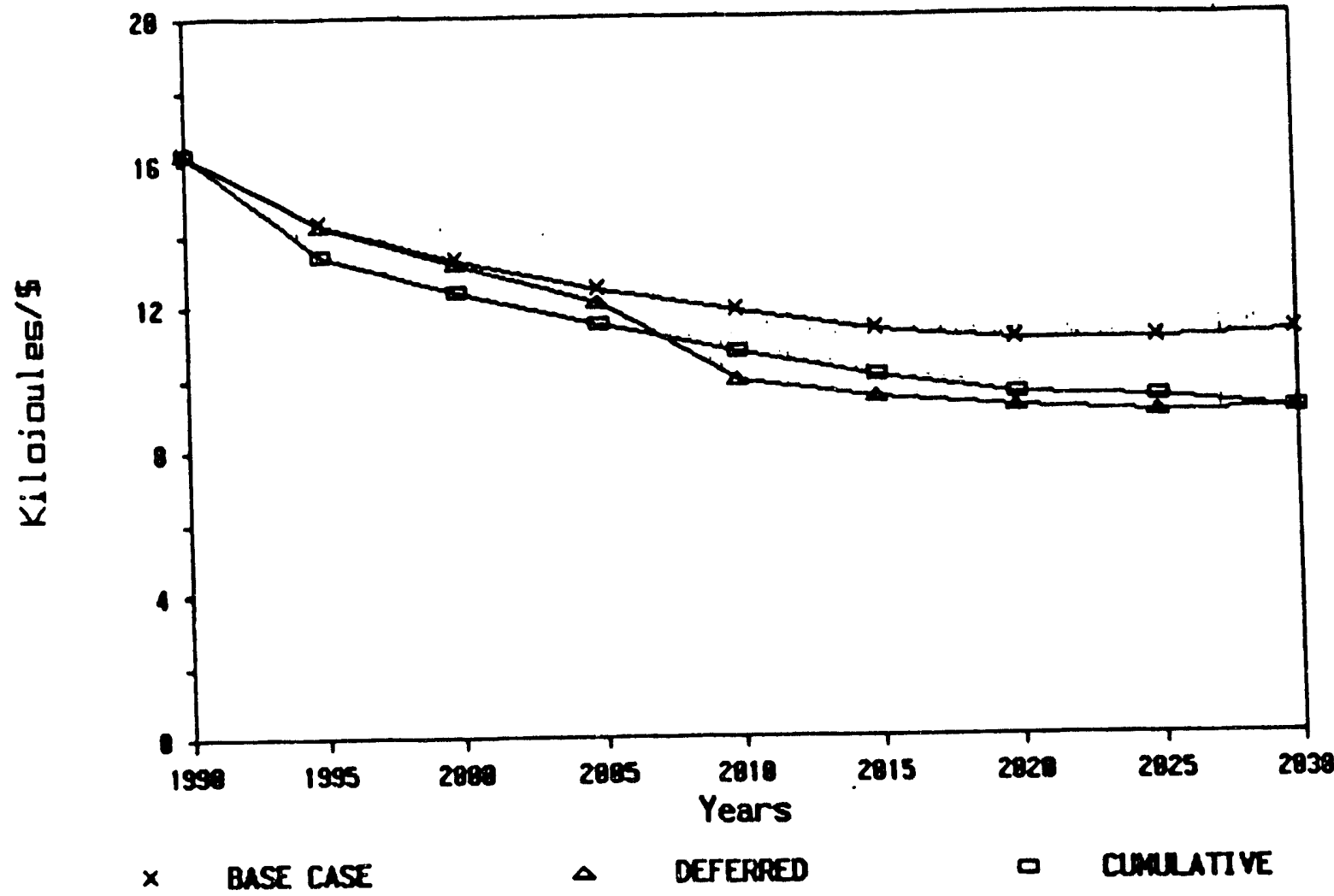


Figure 8

ENERGY INTENSITY: TOTAL UED / \$ GDP

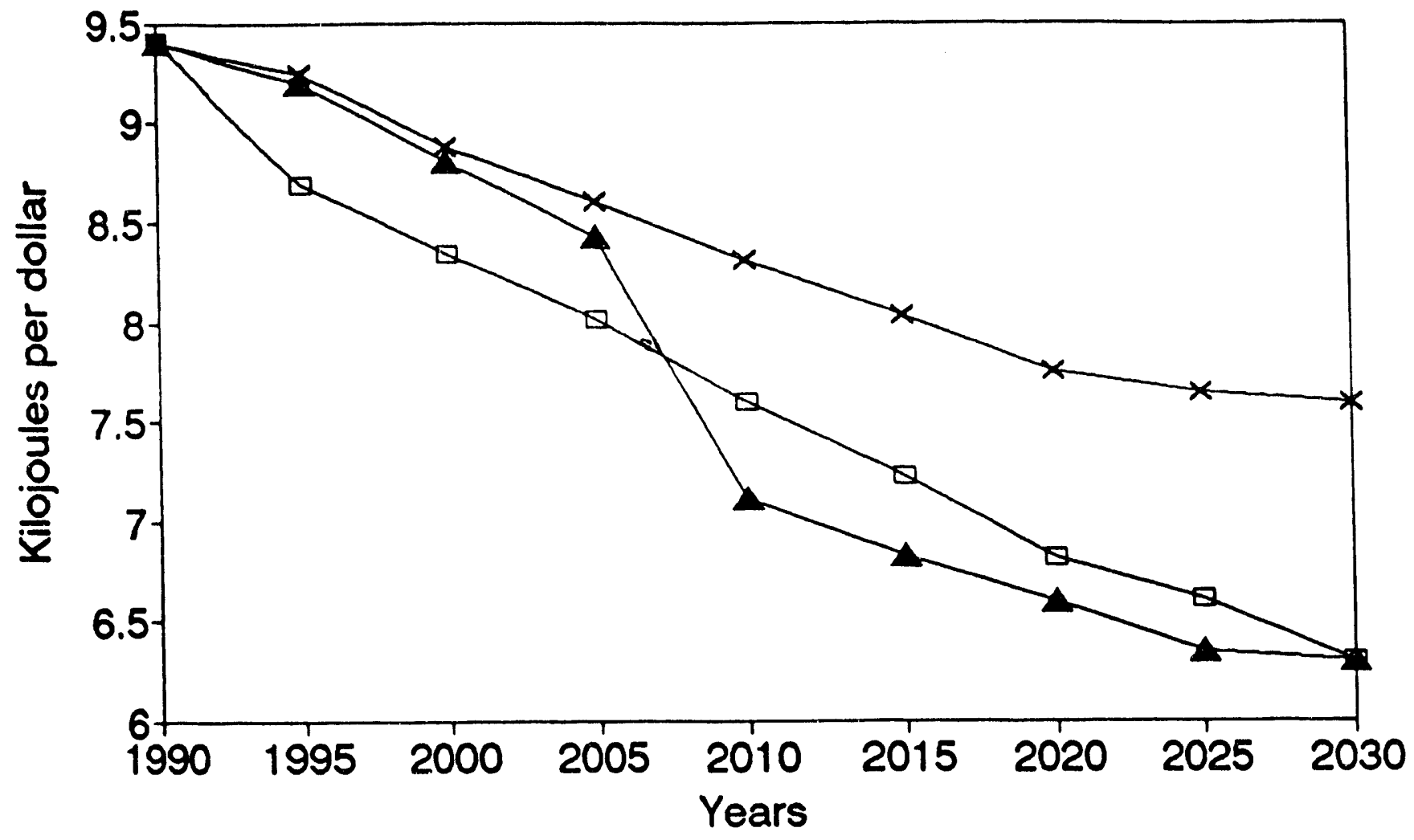

$\rightarrow$ Base Case $\rightarrow$ Deferred Case $\rightarrow$ Cumulative Case 
Figure 9

\section{ELECTRICITY OUTPUT}

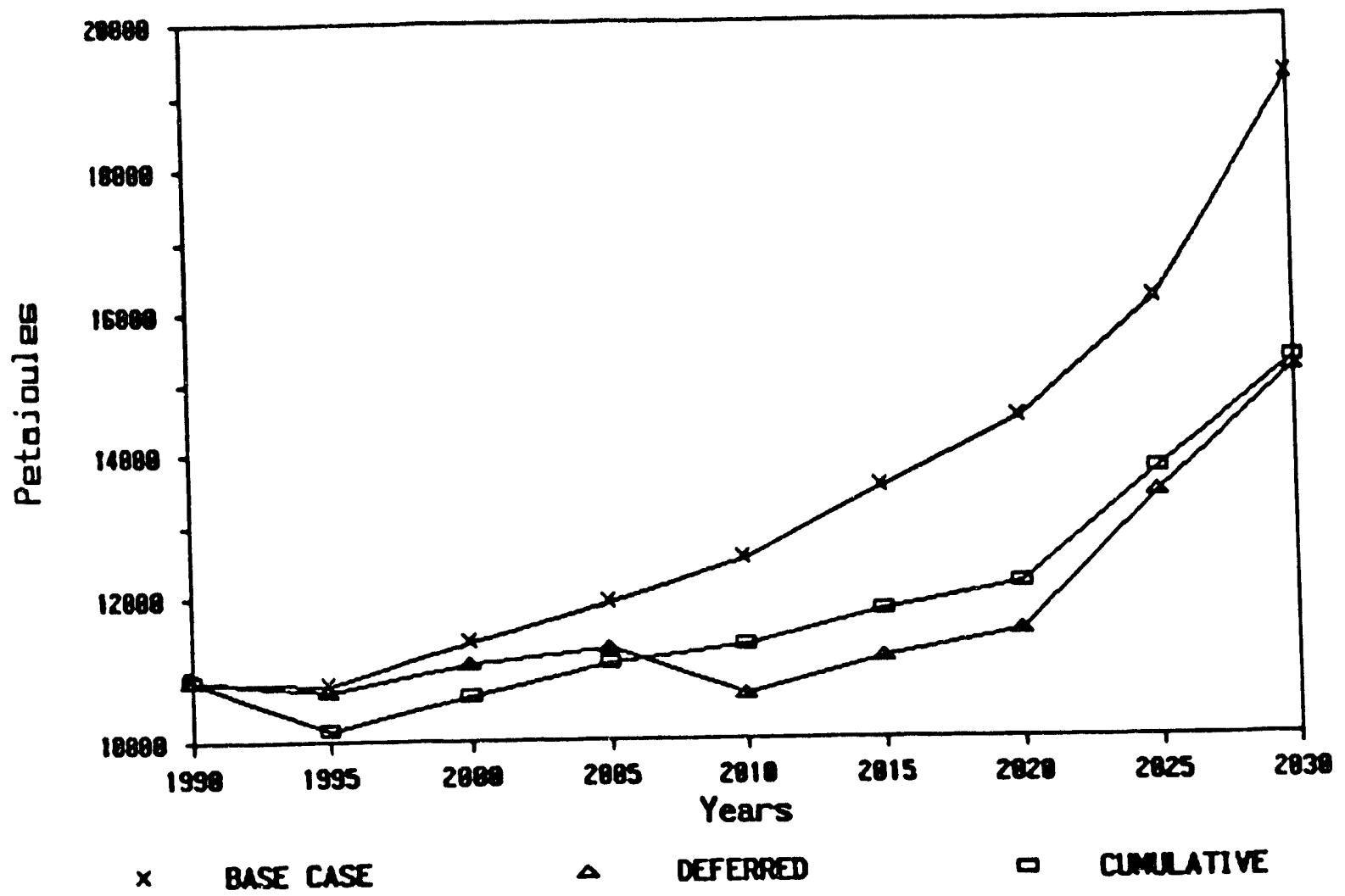


Figure 10

ELECTRICITY OUTPUT BY FUEL USED FOR GENERATION

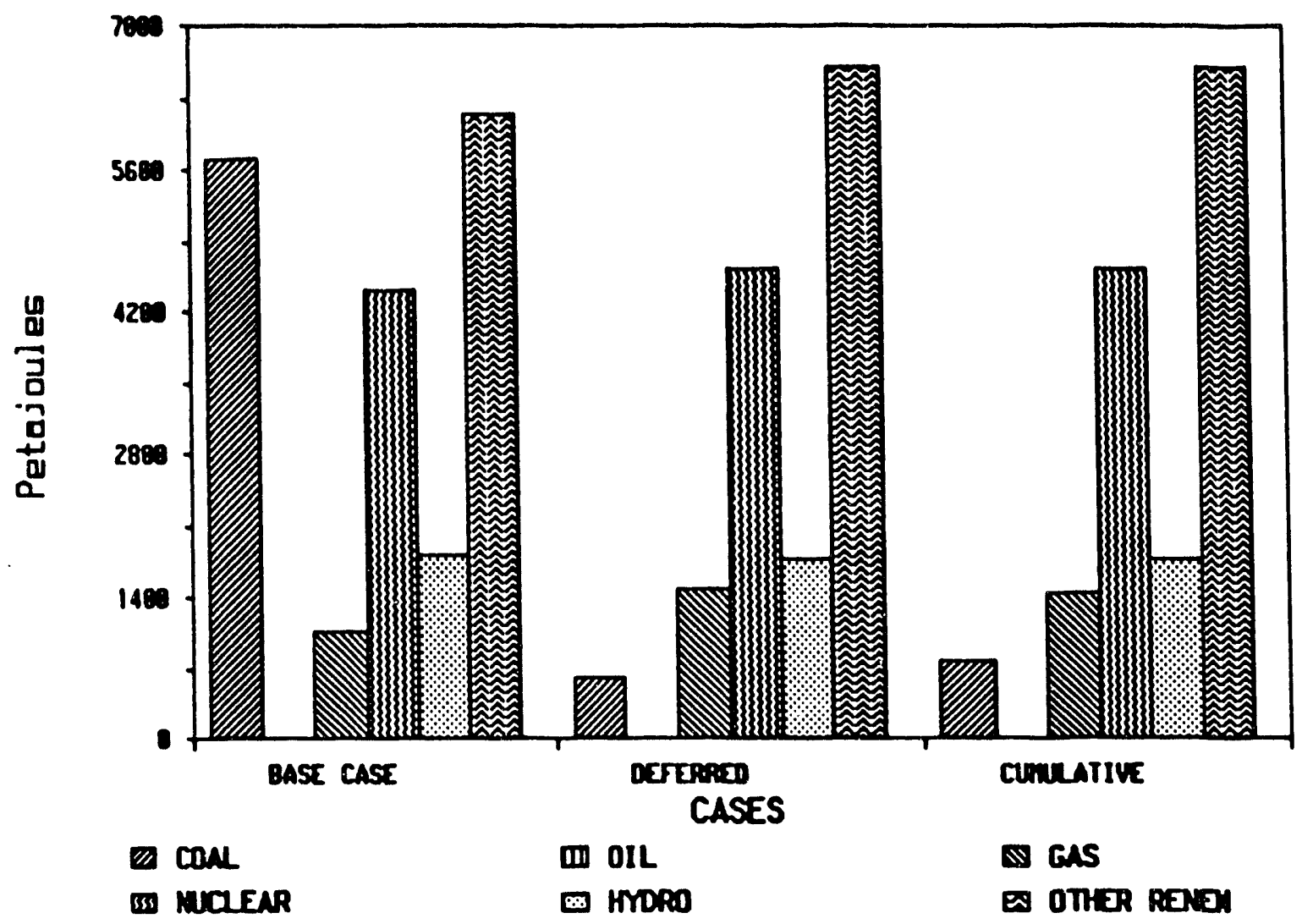


Figure 11

TOTAL $\mathrm{CO}_{2}$ EMISSIONS

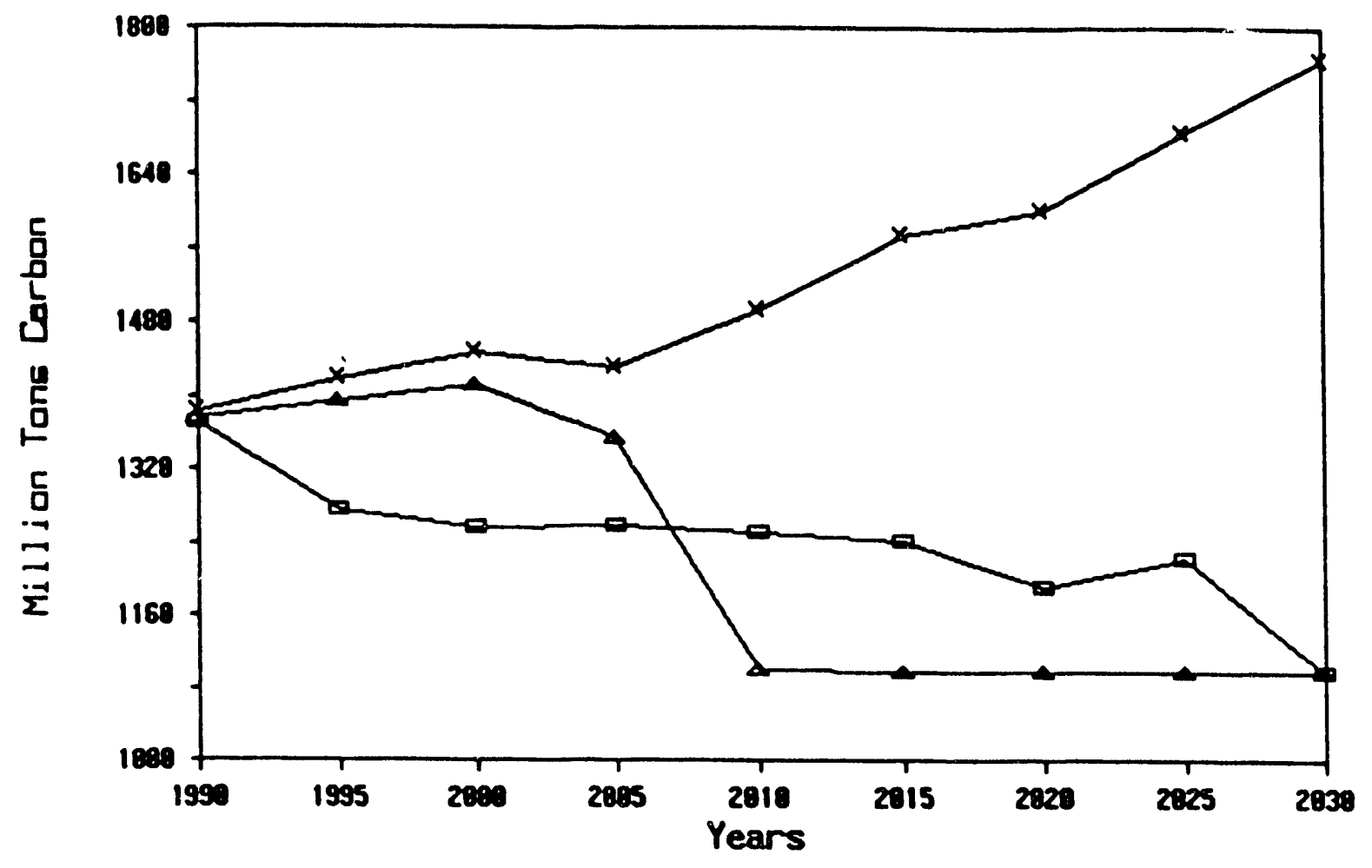

X BASE CASE A DEFERRED O GMULATE 
Figure 12

\section{ENERGY COST}

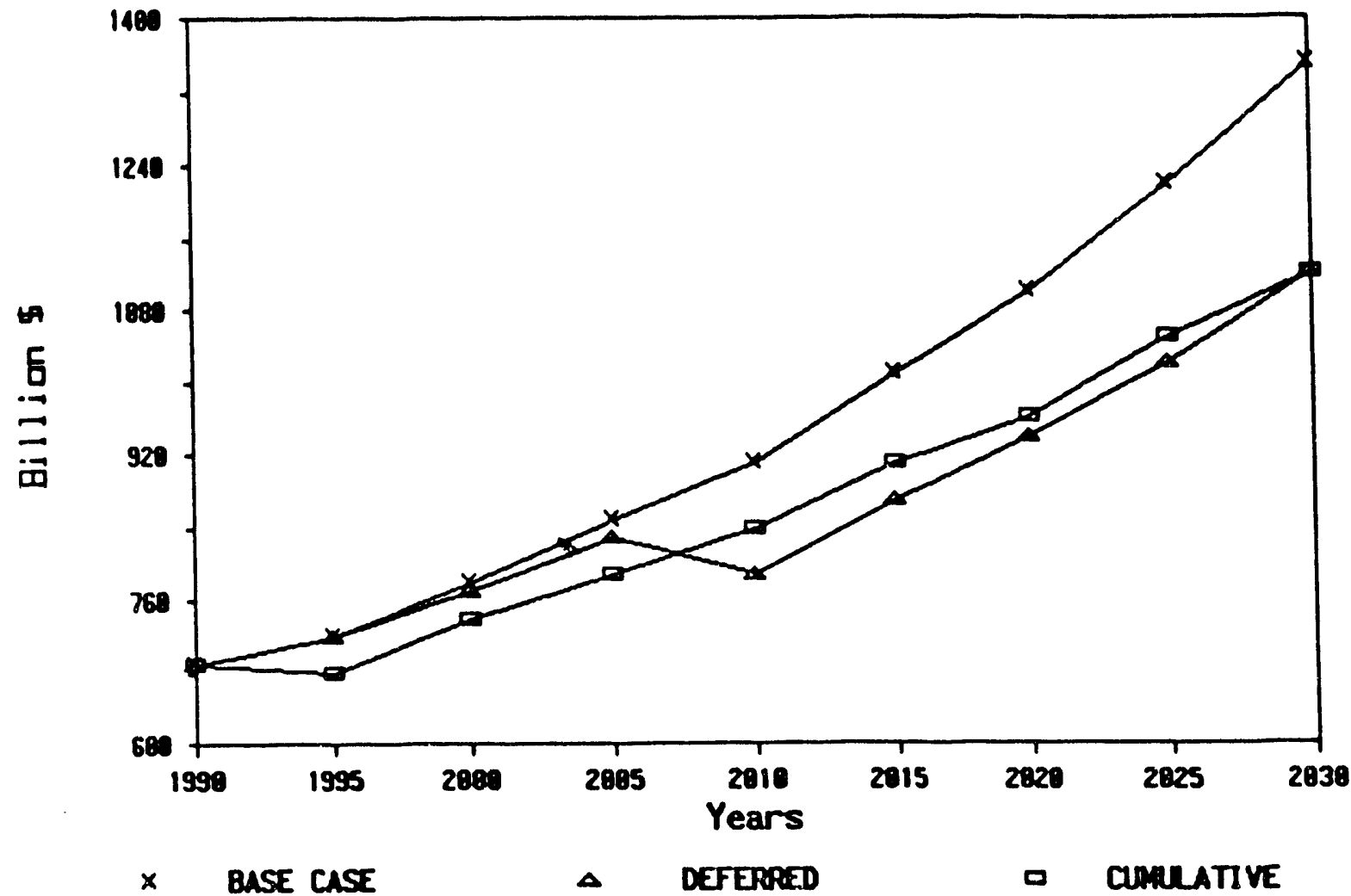


Figure 13

REDUCTION IN GDF FROM BASE CASE

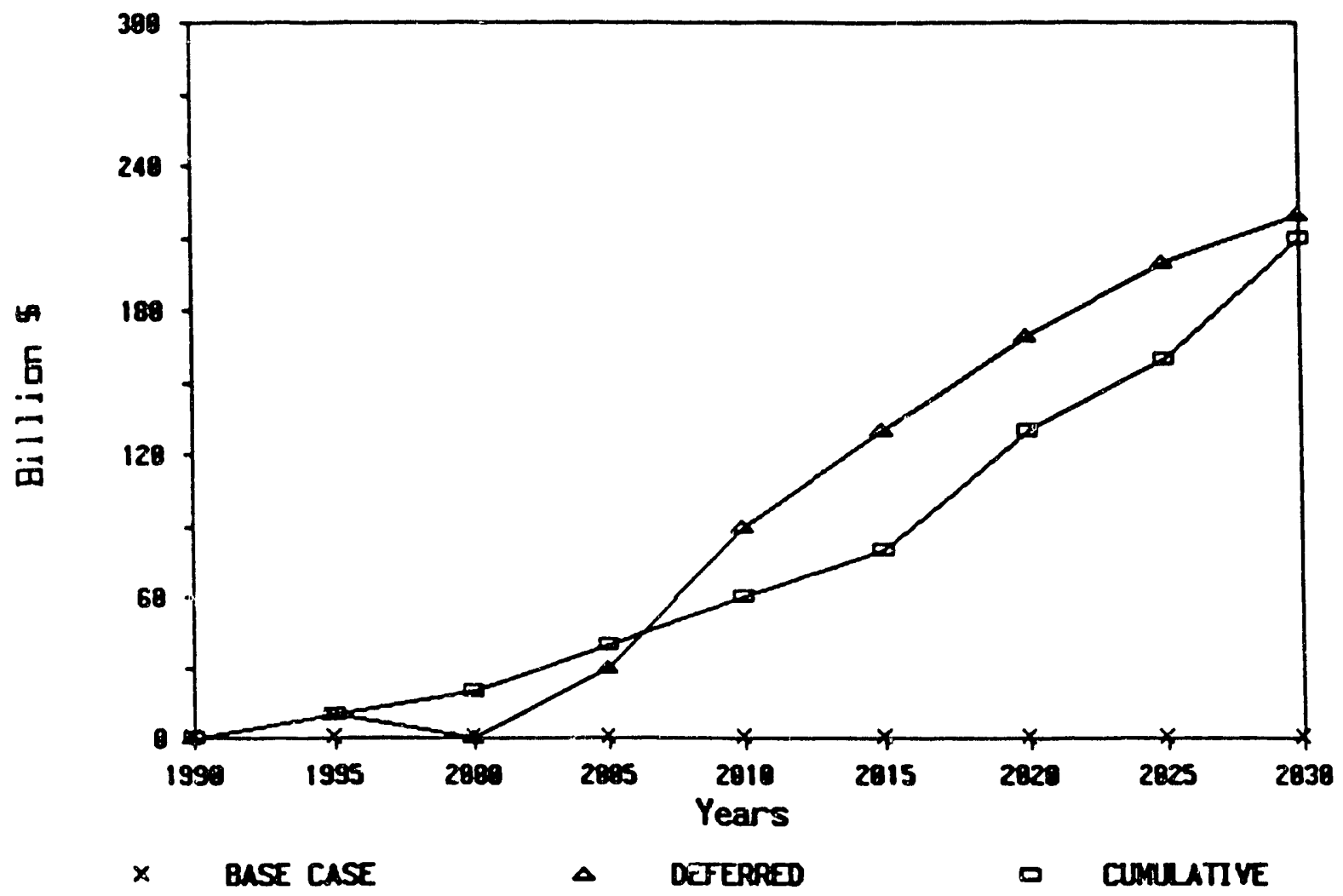


Figure 14

REDUCTION IN INVESTMENT FROM BASE CASE

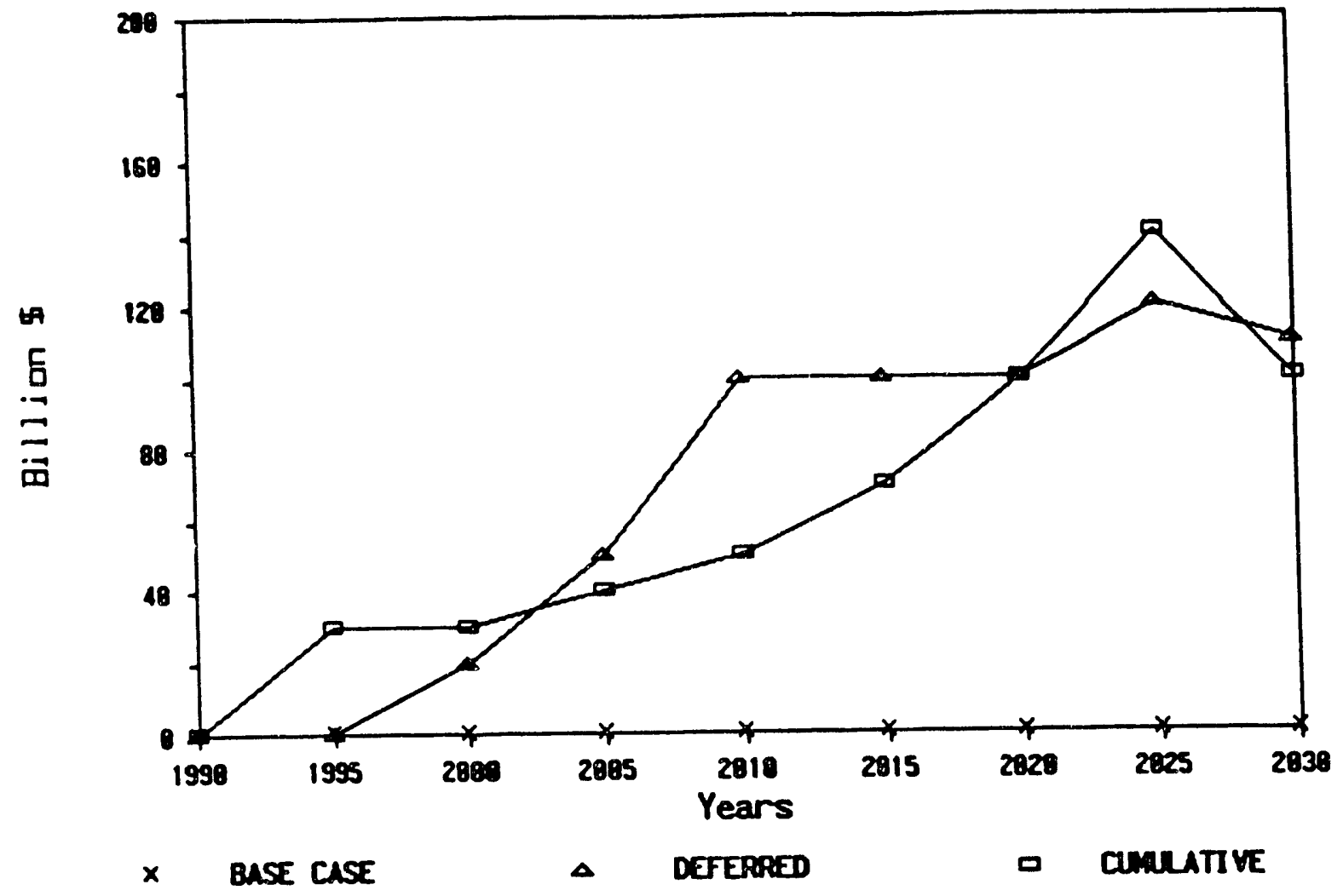


Figure 15

REDUCTION IN CONSUMPTION FROM BASE CASE

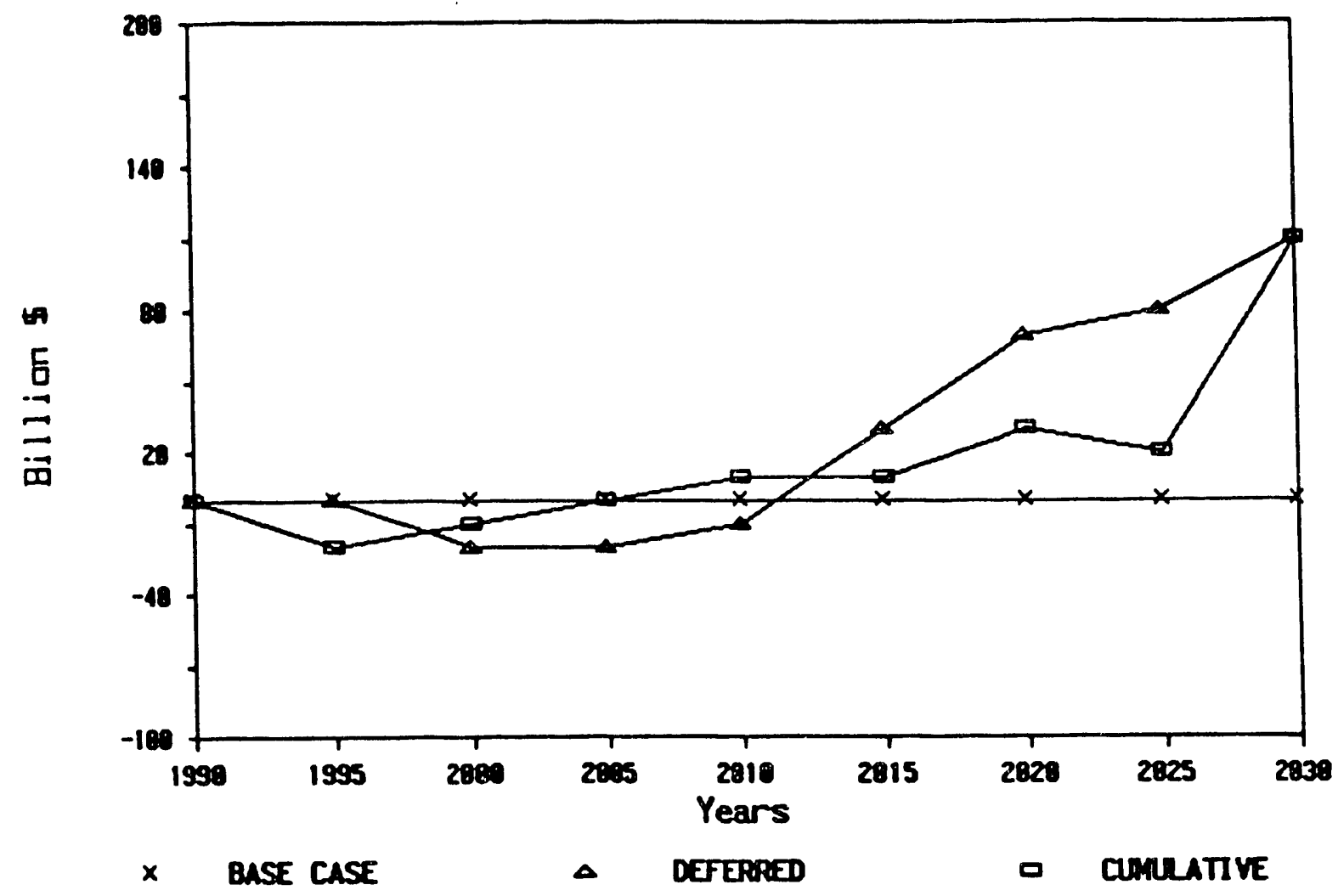


Figure 16

REDUCTION IN ENERGY COST FROM BASE CASE

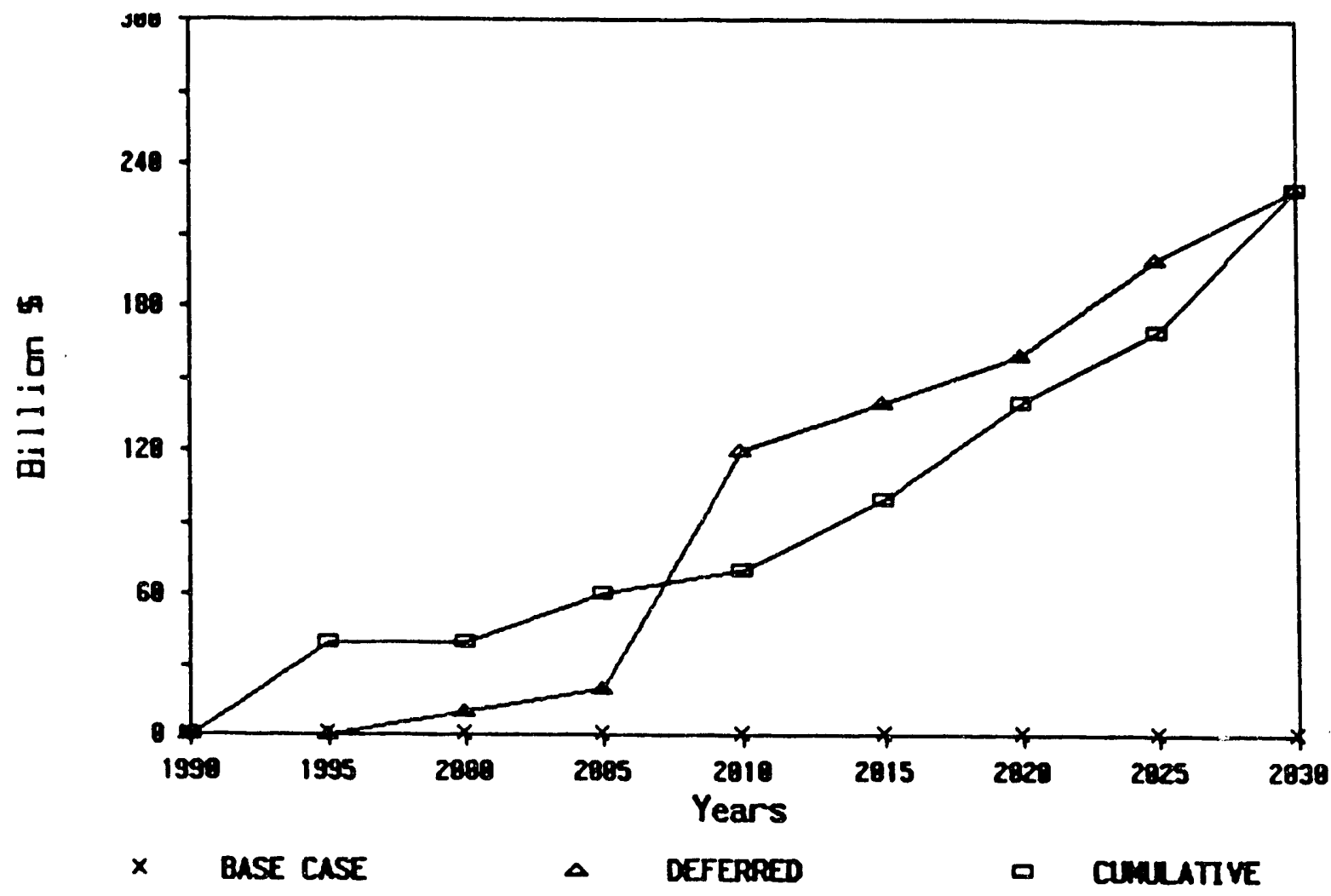


Figure 17

PRICE OF RESIDENTIAL WATER HEAT

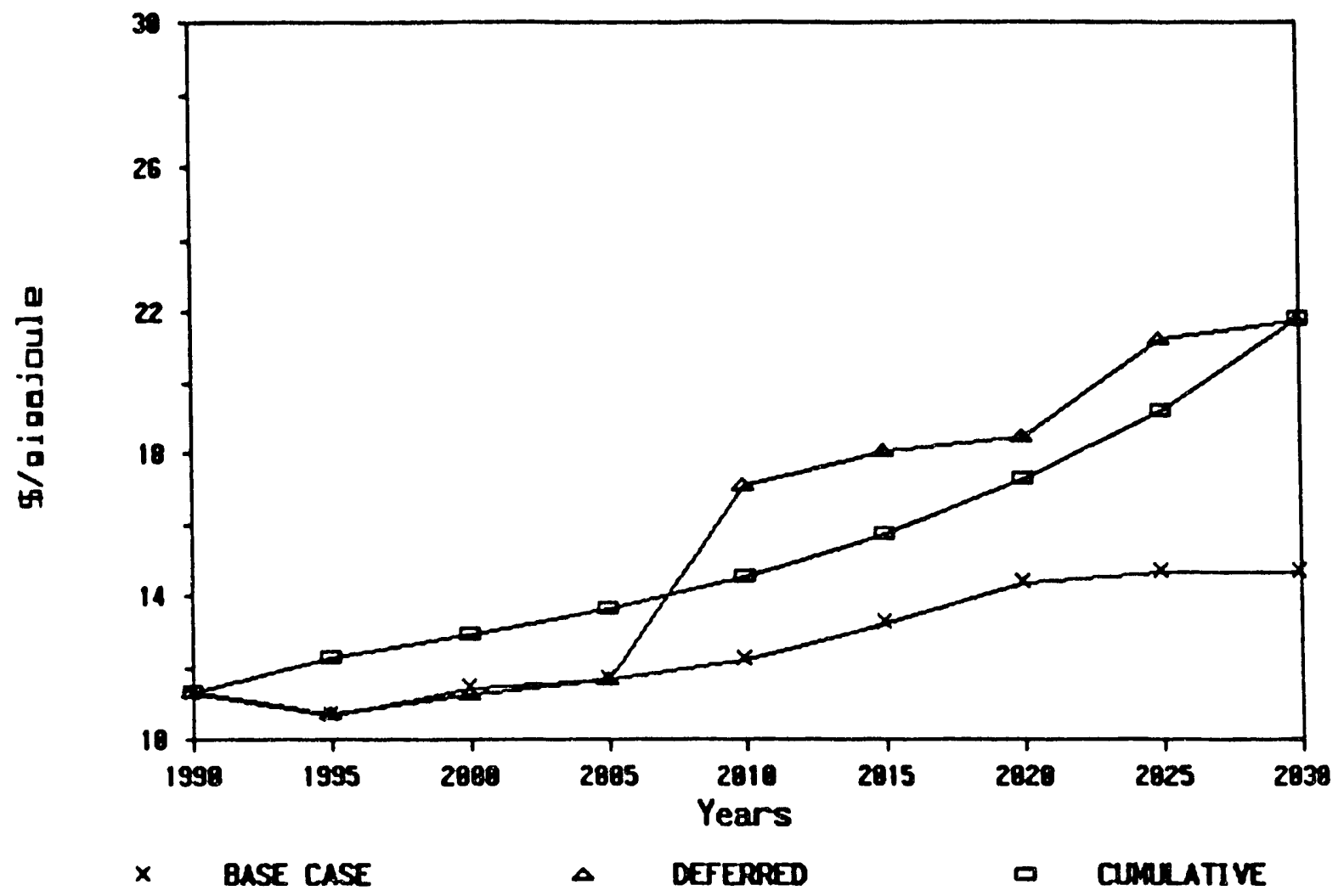


Figure 18

PRICE OF COMMERCIAL SPACE HEAT

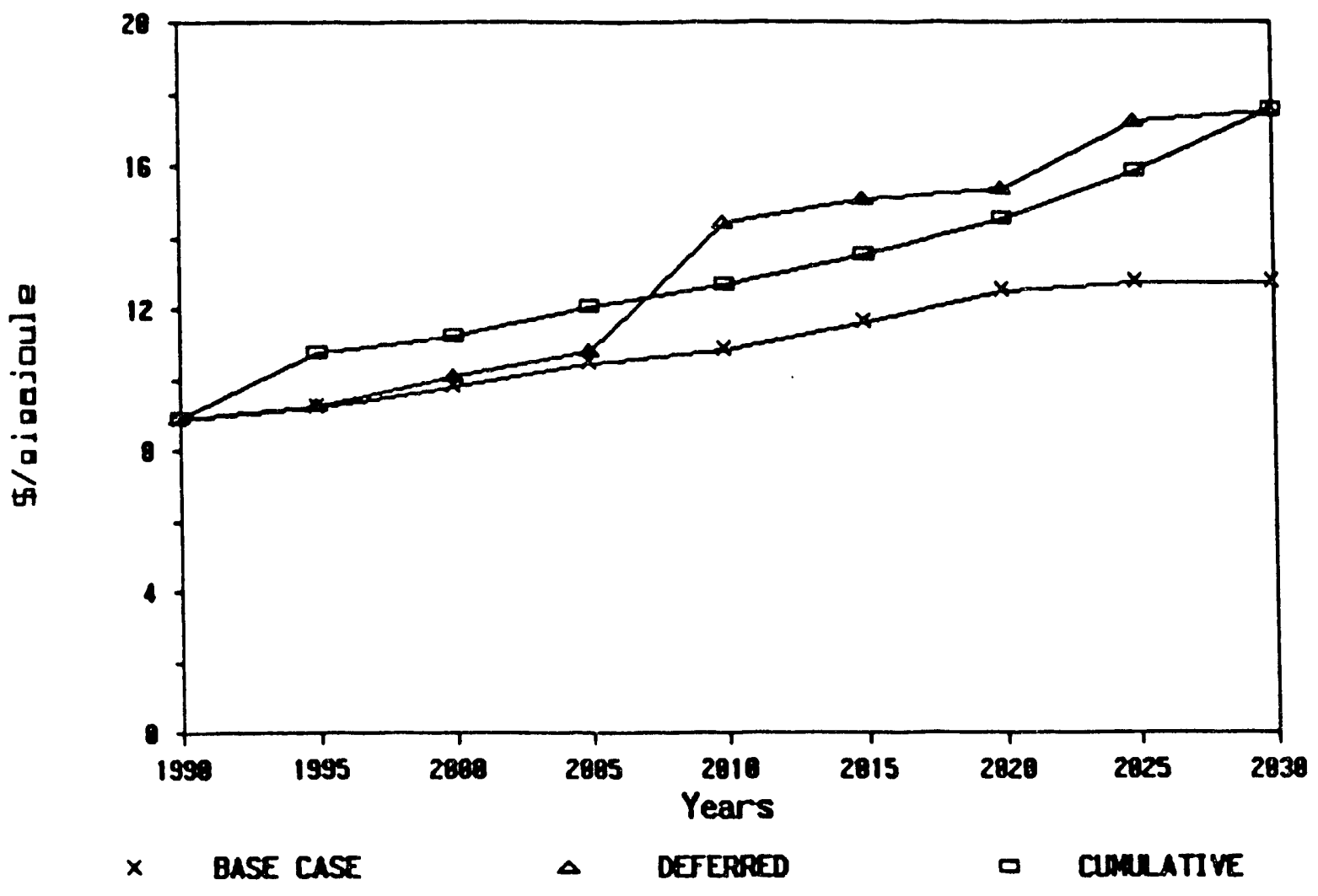


Figure 19

\section{PRICE OF AUTOMOBILE TRANSPORT}

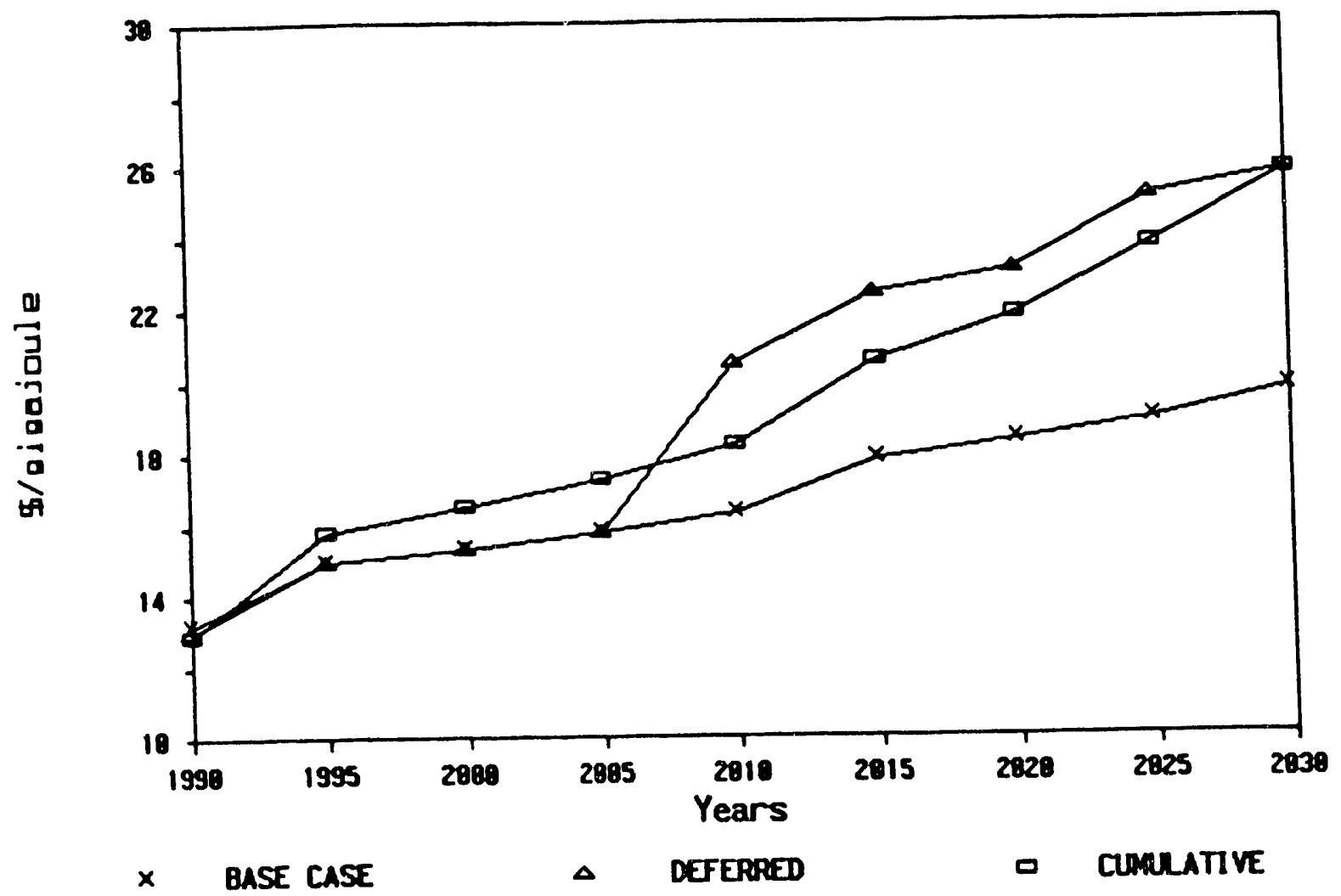


Figure 20

PRICE OF INDUSTRIAL PROCESS HEAT

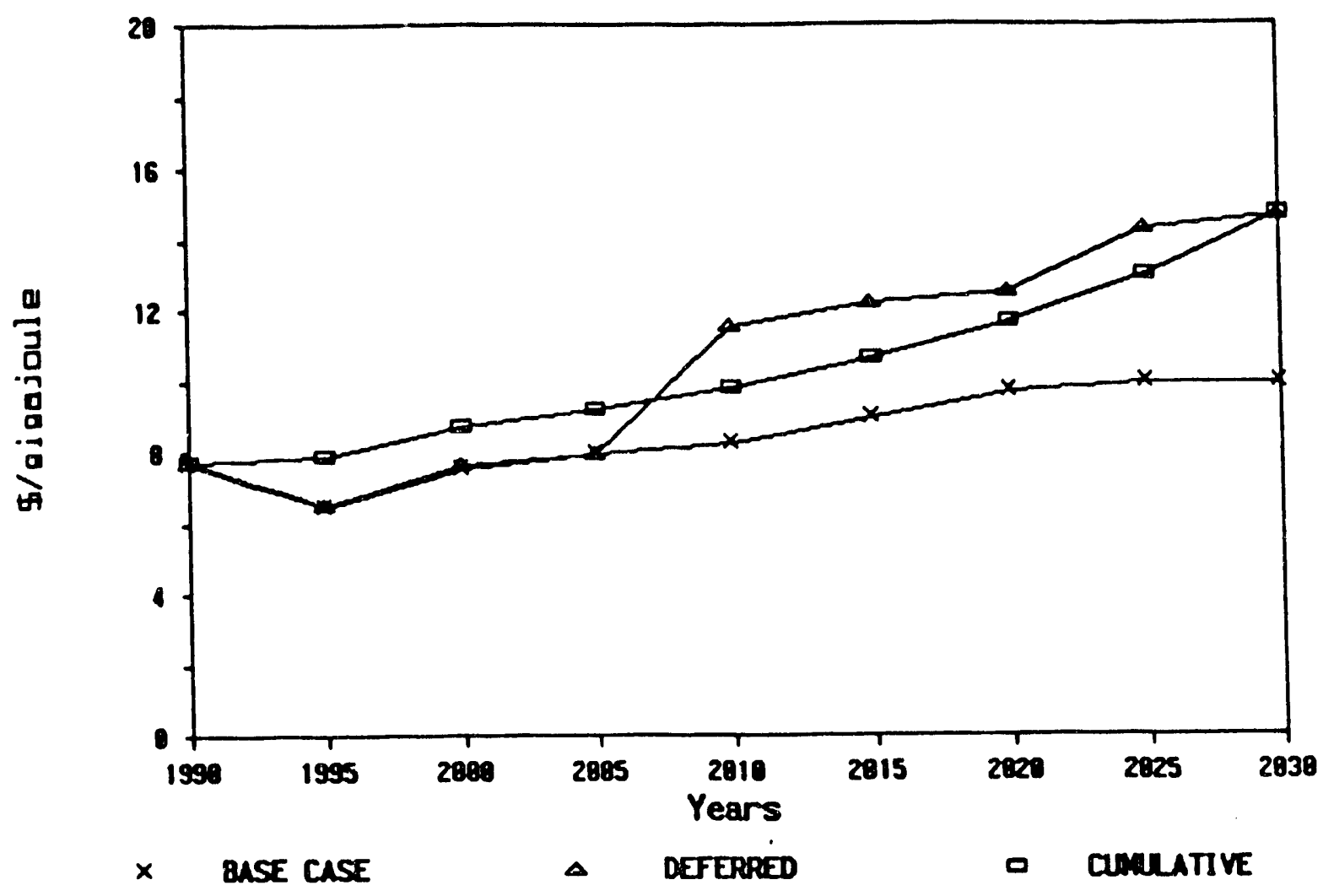


Figure 21

SHADOW PRICE OF CARBON EMISSIONS

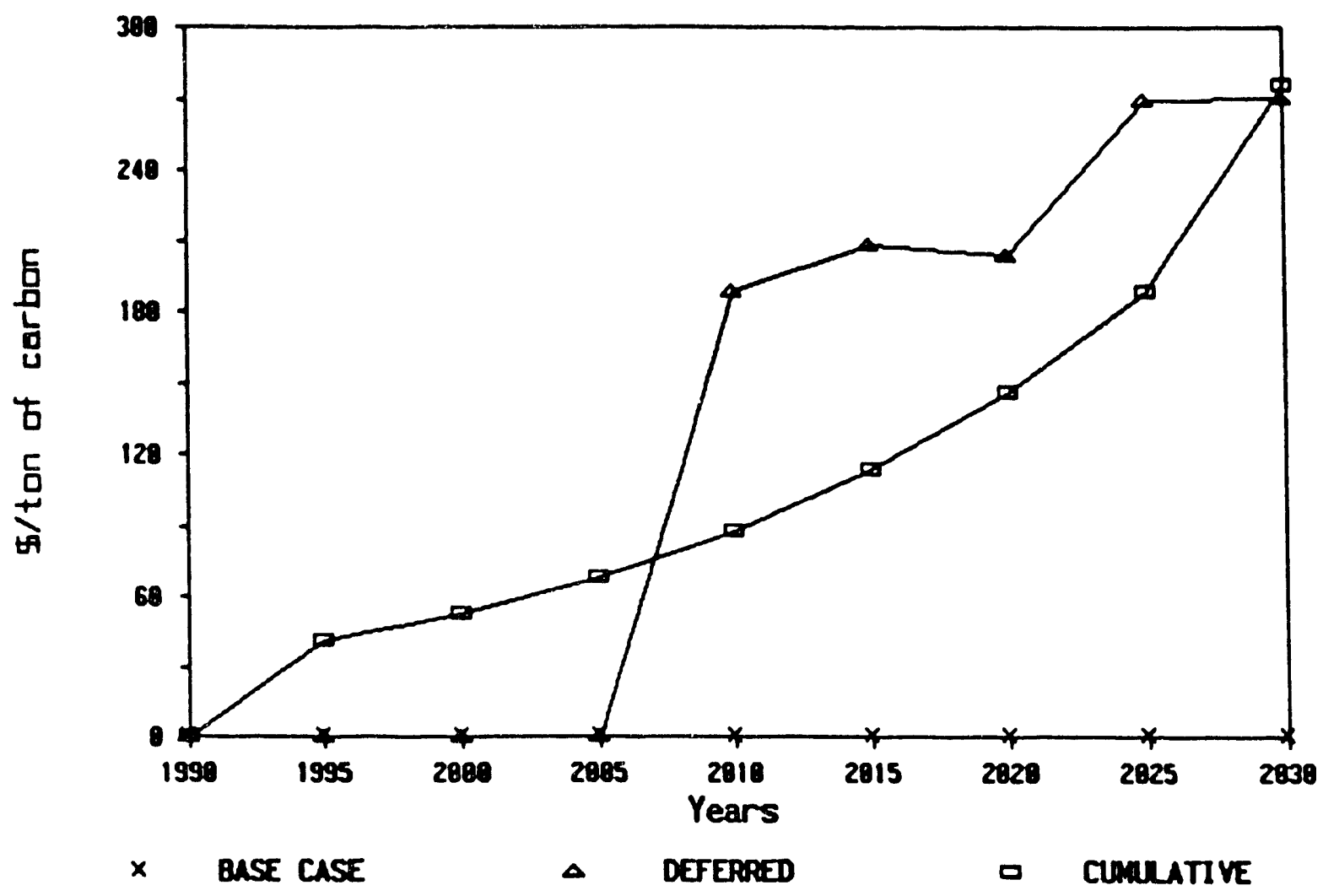

44 
Appendix A: Formulation of the MACRO Submodnl and the linknge P'quations

Nole: MARKAL-MACRO makes we of many of the same idew as ETA-MACRO. Accordingly, this oppeatis incorporates some meterial directly from Manse and Richels (1998).

\section{MACRO decision variablew and notational conveation}

Among the decision variables, the maximand UTILITY is acalar. All other MACRO varialla are time-indexed. Base year values are denoled by $t=1(1990)$. The projection periods are identied a followe: $t=2(1995), 3(2000), \ldots 9$ (2030). For simplicity, the time index $t$ is omitud from the MACRO variables listed below:

UTILITY Sum of discounted logarithms of aggregate consumption

Units of measurement for the following variables are $\$$ trillions per year (measured in dollars of constant 1990 purchasing power) :

$\begin{array}{ll}\text { C } & \text { Consumption } \\ \text { IV } & \text { Investment } \\ \text { EC } & \text { Energy costs } \\ \text { Y } & \text { Production, excluding energy sectors }\end{array}$

Units of measurement for the following variables are $\$$ trillions:

$\mathbf{K}$

Capital slock

Units of measurement for the following variables are exajoules $\left(10^{18}\right.$ joules) per year:

Ddm Demand for useful energy type $d m$ - before adjustment for autonomous energy efficiency improvements

Lower bounds are imposed upon almost all of the variables. Some of the lower bounds are zera Others are positive. These help to avoid unrealistic short-term price-induced demand reductions. Theg also reduce the solution time and/or prevent program calls for undefined numbers, e.g. for the logwithm of zero. The latter class of lower bounds are essential during intermediate iterations, but are intended to be non-binding constraints at an optimal solution. 
It may happen that the units of measurement are cliosen so tlial the logarilhm of consumption in nentive. To allow for this ununual possibility, no lower bound is assigned to the UTILITY variable. It is allowed to take on negative as well as nonnegative values.

All decision variables and sets are indicated by upper case letters; all parameters and sunning indices by lower case letters. The parameters are specified either directly or indirectly through a series of rUSS dats tables which the uset is free to modify. For exsmple, there are files containing the valu for gdpo (the initial GDP), kgdp (the initial capilal-GDP ratio), kpus (capital's value share), dep (the annual depreciation rate for the aggregate capital stock) and the potential GDP growth rate (grow).

\section{The linkage equations}

The stand-alone version of MARKAL is documented elsewhere. For purposes of this report, it is afficient to use the symbol $X_{j}$ to denote MARKAL decision variable $j$. The cost and the useful enery demand rows are connected to the MACRO submodel through special-purpose linkage equations. All other MARKAL constraints are incorporated directly within MARKAL-MACRO.

In MARKAL, there is a fixed demand associated with each form of useful energy during each tine period. In the linked model, we treat these demands as decision variables. There is one for each demand type during each time period. Accordingly, these decision variables are known as $D_{d m, t}$. To comeet them with the MARKAL supply producing activities, we define the supply coefficients supply $_{\mathrm{dm}, \mathrm{t}}$. These coefficients are positive if the MARKAL variable $X_{j}$ is aseociated with supplying the useful demand category $d m$ during time period 1 . We may then link the MARKAL supply activities to the MACRO demand variables through the following equations:

$$
\sum_{j} \text { supply }_{d m, t} x_{j}=\operatorname{aceifac}_{d m, t} D_{d m, t}
$$

where the coefficients aeeifac $\mathrm{dm}, t$ allow for any demand reductions associated with autonomous energy efficiency improvements.

For each variable $\mathrm{X}_{\mathrm{j}}$, the GAMS program calculates a coefficient that describes its impact on the economy-wide energy costs in period $t$. This parameter is known as cost ${ }_{j t}$. It includes the annually recarring costs that appear in the original MARKAL model. It also includes the annual equivalent anortization payment commitments associated with the investment variables for both "residual" and new capacities. This is a minor change, but seems necessary if we are to avoid horizon effects when we 
link the two moxich. MARKAL, employs "Balunge" cocficicinte to cvalunte the worth of terminal capital atocks. This is a dual termination condition. By contrast, MACRO employs a primal termination condition. Following the horizon date, it is supposed that all the MACRO variables will grow a a constant geometric rate.

To avoid excessively rapid expansion of new lechnologies, MARKAL has been modified to include market penetration limits. These are not rigid upper bounds but are soft constraints on the variablea $\mathrm{CAP}_{\text {lch, }}$ (the capacity for technology tch during time period $\mathrm{l}$ ). Growth may be accelerated, but * a rising marginal coot determined by the level of the above-normal expansion variables XCAP $_{\text {lch, }}$. These activities are valued not only because they enable an increase in current output but aleo because they provide a base for future expansion. Letting expf denole the normal five-year expanion factor, we then have:

$$
\operatorname{CAP}_{\text {tch }, t+1} \leq \operatorname{expf} \mathrm{CAP}_{\text {tch,t }}+\mathrm{XCAP}_{\text {tch }, t+1}
$$

With these definitions, the following linkage equations determine the impact of the MARKAL variables upors $\mathrm{EC}_{\mathrm{t}}$, the total energy costs in period $t$ :

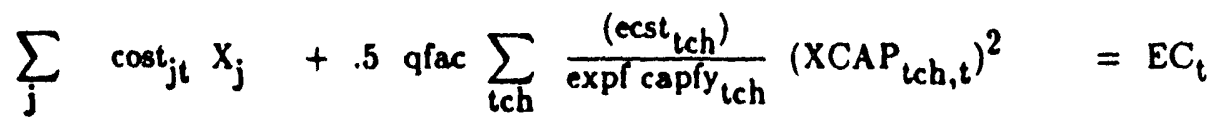

Note that the energy cost equations contain quadratic penalty lerms associated with the abovenormal expansion activities $X_{\text {CAP }}$ tch,t. Suppose that the parameter $q f a c=1$, and that capfy tch represente the maximum level of capacity that can be installed during the first year in which the techoology becomes available. Each penalty coefficient is then chosen so that the marginal cost of providing capacity is doubled if the rate of capacity expansion is twice its normal level during the first period in which the technology becomes available. Over the long run, the marginal costs are determined by the capital charge coefficient associated with each type of capacity. During a period of rapid transition, however, the expansion constraints lead to a period of uvershoot above the long-run leve. These effects are moderated but not eliminated by the operation of the above-normal expansion activities.

A linear penalty form would require less computer time than the quadratic function employed bere With a lincar penalty function, however, there would be a tendency loward bang-bang solutions in which all of the above-normal expansion occurs within a single time period. With quadratic penalies, it is typical for high-cost expansion to take place during more than one period. 
To summarize: The cost corfficients are reralculated, and nre cmployed to link the MARKAL variable to the macro energy costs. Similarly, the supply cormicients link the MARKAL variables to the maxro useful energy demands. Quadratic penalty terms are introduced to smooth the rate of market penetration of new lechnologies. The remainder of the constraint rows are laken over directly from MARKAL.

\section{MACRO conatrainto}

There is a single equation to define the maximand UTILITY, and there is a single constraint referring to the terminal period, TC. All other constraints are time-indexed. The MACRO constraints are as bollowe:

UTIL Discounted utility, sum over all projection periods

USE Uses of total output - allocated among expenditure categories

PRD Sources of total output - inputs to production

CAP Capital accumulation equation

TC Terminal condition on investment and capital stock

These constraints begin with the UTILITY maximand:

UTIL: $\quad$ UTILITY $=\sum_{t=1}^{T-1}\left(\right.$ udf $\left._{t}\right)\left(\log C_{t}\right)+\left(u d f_{T}\right)\left(\log C_{T}\right) /\left(1-\left(1-u d r_{T}\right)^{5}\right]$,

where the utility discount rate for period $t=u d r_{t}=(k p v s / k g d p)-$ depr $-g^{\prime}$ row $_{t}$, and the utility discount factor for period $t=u f_{t}=\prod_{T=0}^{t-1}\left(1-u d r_{T}\right)^{5}$. The exponents of 5 allow for the fact that the firs T-1 periods are each 5 years in length. The terminal period extends an infinite length of time after period $T$. This is the reason for the divisor shown in square brackets.

A numerical example shows how the utility discount rate is determined if the following parameter values are adopted:

$$
\begin{array}{ll}
\text { kpvs }=\text { capital's value share } & =24 \% \\
\mathrm{kgdp}=\text { initial capital-GDP ratio } & =2.4 \text { years } \\
\text { depr }=\text { depreciation rate } & =5 \% / \mathrm{year}
\end{array}
$$




$$
\begin{aligned}
& \text { IIIt rale of relurll oll capilal }=(21 \% / 2.1 \text { ycars })-5 \% / \text { year }=5 \% / \text { year } \\
& \text { grow }_{\ell}=\text { polcnlial growth rale }=2 \% / \text { year } \\
& \therefore \text { udr }_{\mathrm{l}}=\text { utility discount rate }=3 \% / \text { year }
\end{aligned}
$$

The utility discount rate is chosen for descriptive racher than normative purposes. With the logaritbmic single-period utility function, these values ensure that the optimal steady-state growth rate will coixcide with that assumed for the potential GDP. Along an optimal path, the rate of decline in the present value of the marginal utility of consumption will equal the net marginal productivity of capital. (For a calculus-of-variations proof of this proposition, Chakravarty (1969, p. 65).) Moreove, these discount rates mean that the economy-wide savings rate will adjust ciownward (upward) automatically if there is a drop (rise) in the potential GDP growth rate.

The USE equations specify that the gross value of production is to be used for current consumption, investment for building up the stock of capital, and interindustry payments for energy costs:

USE $_{t}: \quad Y_{t}=C_{t}+I V_{t}+E C C_{t} \quad t=0, \ldots, T$

Since the variable $C_{t}$ enters only into the objective function and into equation USE $E_{t}$, the dual variable for this constraint may be interpreted as the present value of the marginal utility of consumption during period t. First-order optimality conditions lead to the Ramsey rule ior the optimal allocation over time between savings, investment and consumption. That is, th marginal productivity of capital determines the rate of decline of these dual variables from one period to the next. All other dual variables for period $t$ have a similar interpretation. They are present value prices. In order to convert them into future values, they must be divided by the dual variables for the USE constraints. According to the numerical example cited above, the net marginal productivity of capital is $5 \%$, and the dual variables for the $U_{S E}$ constraints would decline by about $5 \%$ annually.

Aggregate output during period $t$ is determined by a nested CES (constant elasticity of substitution) production function. The first term indicates that capital and labor may be substituted directly for each other, e.g. through automation of labor-intensive tasks. The higher the wage rate, the more attractive it becomes to adopt automation. Similarly, the second term indicates that esch of the end of energy may be substituted for the others. The higher the price of one of these forms, the more attractive it becomes to adopt another - or to engage in price-induced energy conservation through substituting more capital and labor per unit of output. The production function is of the following specific form: 


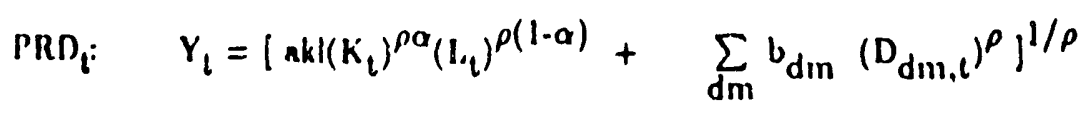

$$
t=1, \ldots, T
$$

At its top level, this nested function has two terms. The first may be interpreted as a value added aggregate of capital and labor based upon a unitary elasticity of subetitution. The second is a separalle energy aggregate. In effect, we are making the assumption of "want independence". See Frisch (1959).

The parameter $\alpha$ (also known as kpos) may be interpreted as the optimal value share of capital in the value added aggregate. The exponent $\rho$ is related to ESUB (the elasticity of substitution between the energy and the value added aggregates) through the following equation: $\rho=1 \cdot(1 / E S U B)$. For the concepts and terminclogy of macroeconomic production functions and neoclassical growth theor, see Aller. (1968).

The labor fr.ce (measured in "efficiency units") is an exogenously specified index number, $L_{t}$. Its values are: $L_{0}=1$, and $L_{t+1}=(1+\text { grow })^{5} L_{t}$.

Given the values for the two exponents $\alpha$ and $\rho$, a base year benchmarking procedure is empleyed to determine the coefficients akt and $b_{d m}$ in the production function. Let pref $d m$ denote the "refence" price of useful energy form $\mathrm{dm}$ in the base year. Neglecting the time subscripts for this year, a first-order optimality condition implies that :

$$
\delta \mathrm{Y} / \partial \mathrm{D}_{\mathrm{dm}}=\left(\mathrm{Y} / \mathrm{D}_{\mathrm{dm}}\right)^{1-\rho} b_{\mathrm{dm}}=\operatorname{pref}_{\mathrm{dm}}
$$

Except for $b_{d m}$, each element in the preceding equation is known from the base year statistics or from other input parameters. After solving for $b_{\mathrm{dm}^{m}}$, we employ the base year values directly within the soduction function. The base year labor force index is 1 . Since this nested CES production function is based upon constant returns to scale, we may rely upon exhaustion-of-product to solve the following equation directly for the parameler akt

$$
Y^{\rho} \quad=a k ! K^{a \rho}+\sum_{d m} b_{d m}\left(D_{d m, t}\right)^{\rho}
$$


The MCAP equations describe the dynamics of capital accumulation. Willin each 5-year period, act new capilal formation is determined by gross investment less depreciation. Let the annual depreciation rate be indicaled by depr. Then the five-year capital survival fraction, srv $=(1-\text { depr })^{5}$. Since investment is measured as an annual now, an accumulation factor of 2.5 is applied to the beginaiag and ending rate of investment 80 as to determine net new capital formation during the fiveyear period as a whole:

$\operatorname{MCAF}_{t+1}: \quad K_{t+1}=\operatorname{serv} K_{t}+2.5\left[\operatorname{tsrv} I_{t}+I_{t+1}\right] \quad t=0, \ldots, T-1$

where $b_{0}=($ grow + depr $) K_{0}$.

At the end of the planning horizon, a terminal constraint is applied to ensure that the rate of investaent is adequate to provide for replacement and net growth of the capital stock during the subsequent periods.

TC:

$$
\mathrm{K}_{\mathrm{T}}(\text { grow }+ \text { depr }) \leq \mathrm{I}_{\mathrm{T}}
$$

In effect, it is assumed that the MACRO variables will grow at a constant geometric rate during the post-horizon period. This is a primal terminal condition. It reduces "horizon effects", but is not guaranted to eliminate them entirely. For a more complete discussion of terminal conditions, see Sworonos (1985). 

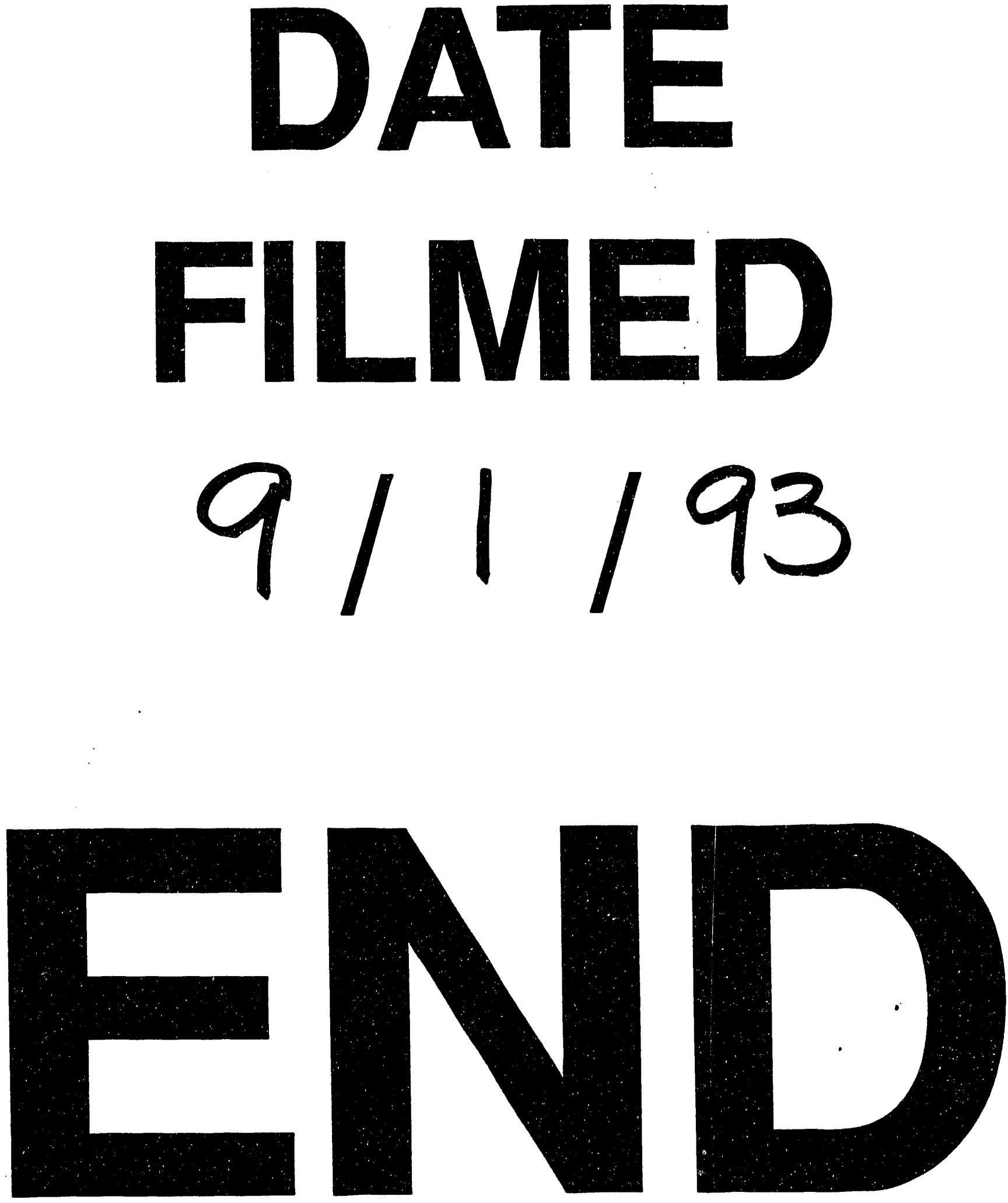
